\title{
Unravelling Vitamins as Wonder Molecules for Covid-19 Management via Structure-based Virtual Screening
}

\section{Medha Pandya ( $\square$ megsp85@gmail.com )}

The KPES Science College,M.K Bhavnagar University, Bhavnagar,Gujarat,India,

\section{Sejal Shah}

Department of Microbiology, School of Science, RK. University, Rajkot, Gujarat, India

\section{Dhanalakshmi Menamadathil}

Research and Development Centre, Bharathiar University, Marudhamalai Rd, Coimbatore, TamilNadu, 641046, India.

\section{Ayushman Gadnayak}

Centre for Genomics \& Biomedical Informatics, IMS and SUM Hospital, Siksha "O" Anusandhan (Deemed to be University), Bhubaneswar, Odisha 751003, India

\section{Tanzil Juneja}

Department of Microbiology, School of Science, RK. University, Rajkot, Gujarat, India

\section{Amisha Patel}

Department of Microbiology, School of Science, RK. University, Rajkot, Gujarat, India

\section{Kajari Das}

Department of Biotechnology, College of Basic Sciences and Humanities, Orissa University of Agriculture and Technology, Bhubaneswar 751 003, Odisha, India.

\section{Jayashankar Das}

Centre for Genomics \& Biomedical Informatics, IMS and SUM Hospital, Siksha "O" Anusandhan (Deemed to be University), Bhubaneswar, Odisha 751003, India

\section{Research Article}

Keywords: Vitamins, Furin, B12, viral drug targets, Covid-19

Posted Date: January 13th, 2021

DOl: https://doi.org/10.21203/rs.3.rs-144177/v1

License: @ (1) This work is licensed under a Creative Commons Attribution 4.0 International License. Read Full License 


\title{
Unravelling Vitamins as Wonder Molecules for Covid-19 Management via Structure-based Virtual Screening
}

\author{
Medha Pandya ${ }^{1 *}$, Sejal Shah ${ }^{2}$, Dhanalakshmi. $\mathbf{M}^{3}$, Tanzil Juneja ${ }^{2}$, Amisha Patel ${ }^{2}$,
} Ayushman Gadnayak ${ }^{4}$, Kajari Das ${ }^{5}$, Jayashankar Das ${ }^{4 *}$

1. The KPES Science College, M.K Bhavnagar University, Bhavnagar, Gujarat, India.

2. Department of Microbiology, School of Science, RK. University, Rajkot, Gujarat, India.

3. Research and Development Centre, Bharathiar University, Marudhamalai Rd, Coimbatore, TamilNadu, 641046, India.

4. Centre for Genomics \& Biomedical Informatics, IMS and SUM Hospital, Siksha "O" Anusandhan (Deemed to be University), Bhubaneswar, Odisha 751003, Indial

5. Department of Biotechnology, College of Basic Sciences and Humanities, Orissa University of Agriculture and Technology, Bhubaneswar 751 003, Odisha, India. Corresponding authors: megsp85@gmail.com, medhapandya85@gmail.com dasjayashankar@gmail.com

\begin{abstract}
The emergence situation of coronavirus disease 2019 (COVID-19) pandemic has realised the global scientific communities to develop strategies for immediate priorities and long-term approaches for utilization of existing knowledge and resources which can be diverted to pandemic preparedness planning. Lack of proper vaccine candidate and therapeutic management has accelerated the researchers to repurpose the existing drugs with known preclinical and toxicity profiles, which can easily enter Phase 3 or 4 or can be used directly in clinical settings. We focused to justify even exploration of supplements, nutrients and vitamins to dampen the disease burden of the current pandemic may play a crucial role for its management. We have explored structure based virtual screening of 15 vitamins against nonstructural (NSP3, NSP5, ORF7a, NSP12, ORF3a), structural (Spike \& Hemagglutinin esterase) and host protein furin. The in silico analysis exhibited that vitamin B12, Vitamin B9, Vitamin D3 determined suitable binding while vitamin B15 manifested remarkable H-bond interactions with all targets. Vitamin B12 bestowed the lowest energies with human furin and SARS-COV2 RNA dependent RNA polymerase. Furin mediated cleavage of the viral spike glycoprotein is directly related to enhanced virulence of SARS-CoV-2. In contrast to these, vitamin B12 showed zero affinity with SARS-CoV-2 spike protein. These upshots intimate that Vitamin B12 could be the wonder molecule to shrink the virulence by hindering the furin mediated entry of spike to host cell. These identified molecules may effectively assist in SARS-CoV-2 therapeutic management to boost the immunity by inhibiting the virus imparting relief in lung inflammation.
\end{abstract}

Keywords: Vitamins, Furin, B12, viral drug targets, Covid-19, 


\section{Introduction}

The outbreak of novel coronavirus disease (COVID-19) has been declared as the global pandemic by the world health organization. Currently, the world is facing an awful pandemic of coronavirus disease 2019 (COVID-19) caused by severe acute respiratory syndrome coronavirus 2 (SARS-CoV-2), represents an unprecedented challenge to the medical sciences as the virus is highly contagious [1]. The first case was reported in Wuhan city of China in December 2019 and spread across the globe through human-to-human transmission. Worldwide there are 77,228,903 confirmed cases of COVID-19, including 1,718,470 deaths have been reported for the across 216 countries dated on $24^{\text {th }}$ December 2020 (https://covid19.who.int/). Since last two decades, three outbreaks of coronavirus ensued worldwide: (i) severe acute respiratory syndrome coronavirus (SARS-CoV), (ii) Middle East respiratory syndrome coronavirus (MERS-CoV) and (iii) SARS-CoV-2 [2]. Coronaviruses are single-stranded RNA viruses (+ssRNA) with 26 to $32 \mathrm{~kb}$ in size and appear with crown-like structure due to presence of spike glycoproteins on their surface. They are categorized into four genera: Alpha $(\alpha)$, Beta $(\beta)$, Gamma $(\gamma)$, and Delta $(\delta)$ coronavirus. $\beta$-coronavirus include SARS-CoVs, MERS-CoVs, and SARS-CoV-2 and can infect both humans and animals [3]. SARS-CoV and MERS-CoV have developed mechanisms to reduce IFN production ensuing increased inflammatory host responses, which produce powerful inflammatory cytokines (cytokine storm) and severe lung injury [4]. Cytokine storm found in SARS-CoV and MERS$\mathrm{CoV}$ infected patients, would correlate with disease severity and poor prognosis [5].

SARS-CoV-2 also known as novel coronavirus (nCOV-2) encodes for various structural as well as non-structural proteins facilitates viral entry as well as replication inside the host cell. SARS-CoV-2 encodes the envelope spike glycoprotein which binds to its cellular receptor, angiotensin-converting enzyme 2 (ACE2) and stimulates membrane fusion and endorsements of the virus into human cells $[6,7]$. The affinity of SARS-CoV-2 towards the ACE-2 is much higher compared to SARS-CoV, may be reason for higher severity in terms of transmission compared to SARS- CoV [8]. Other than S and hemagglutinin-esterases (HE) glycoprotein, SARS-CoV-2 encodes various nonstructural proteins, which include the main protease (Mpro /3CL pro), papain-like protease (PL pro), RNA dependent RNA polymerase (RdRp) and Nsp3 largest protein encoded by coronavirus. Availability of SARS-CoV-2 structural and non-structural proteins has given the opportunity for structure-based screening of existing compounds against them. Various studies have been already done on molecular docking-based screening of existing antiviral, antibacterial and other FDA approved drugs [9]. 
Although the combat to find a specific therapy for the recent pandemic of COVID-19 is still on the way, clinically approved antiviral drug or vaccine is though developed, the effect is yet to be confirmed against the SARS-CoV-2. Several drugs have been reported for in vitro activity against different coronaviruses. Drug repositioning may offer a strategy hence, many drugs have been repurposed, including Remdesivir, Hydroxychloroquine and Chloroquine, Umifenovir (Arbidol), Lopinavir-Ritonavir, Favipiravir (Avigan), Oseltamivir (Tamiflu), Sofosbuvir, galidesivir and tenofovir showed promising results for treatment of newly emerged strain of coronavirus $[10,11]$. Other antiviral drugs including ribavirin, zanamivir, acyclovir, peramivir and ganciclovir which are commonly used in clinical practice, are currently not recommended for COVID-19 [12]. Numerous computational theranostic approaches yet developed for the infectious disease $[13,14]$. Due to lack of specific vaccines or therapeutic drugs, many supporting agents used as adjunctive therapies for COVID-19 patients which includes Azithromycin, Epoprostenol, Tocilizumab, Sirolimus, Corticosteroids, Sarilumab, Colchicine, Indomethacin, Thiazolidinediones and Ibuprofen [13]. Recently, several possibilities such as targeting viral binding receptors (ACE2) and spike proteins, small-molecule drugs, monoclonal antibodies, stimulating an immune response, peptides, etc. are being discovered against emerging SARS-CoV-2 infection. Lot of research efforts have been carried out to develop vaccines around the globe. Until we have specific vaccines or therapeutic drugs targeting SARS-CoV-2, "repurposed" drugs that have been approved by the FDA in the USA for other indications have been used to treat COVID-19 patients.

Currently, there is no appropriate drug treatment or vaccine against the SARS-CoV-2 virus. Until these become available, one must include suitable and balanced nutrition for appropriate body functioning and enhancing of the immune system especially with the help of various vitamins. Several vitamins, minerals and herbs have a treasured effect on mitochondrial function. Vitamins (Vita.) including B1, C (Ascorbic acid), D, E and Omega-3, minerals such as magnesium and manganese and herb like thyme play an important role on the innate system under the virus infection [15]. The study suggests the need to diet with the higher content of Vitamin C [16] and Vitamin B- Complex micro-nutrients to manage this pandemic successfully [17]. Due to anti-inflammatory properties, zinc has been suggested to limit the cytokine storm [18]. Petite study has been reported till date for role of vitamins to treat COVID 19 pandemic. Hence, we, here using in silico study reports the inhibitory effects of different Vitamins on SARS-COV-2 structural and non-structural proteins. 


\section{Materials and Methods}

\subsection{Retrieval of vitamin structures}

Total of 15 vitamins were retrieved from the PubChem database (Table S1). The threedimensional structure of the molecules was downloaded in SDF format and the molecules whose only two-dimensional structures were available, were converted into the threedimensional form using Marvin Sketch and the best confirmation obtained is minimised in semi-empirical PM3 method using Polak-Ribeire algorithm in Hperchem Student evaluation version. The minimised structure is then converted to pdbqt by AutoDockTools [19].

\subsection{Protein preparation}

The high resolution three dimensional X-ray crystal structures of the target proteins of SARS-CoV-2 retrieved from protein data bank (PDB) (http://www.rcsb.org/) using their accession IDs 6LU7 (main proteases), 6M71(RdRp), 6vxx (spike protein), 6Y3Y(Hemagglutinin esterase (HE)), 6w6y (NSP3), 4non (NSP10), 6w37(ORF7a),6xdc (ORF3a)and Human proprotein convertase furin (5jxg) respectively.The selected target proteins were prepared for docking using AutoDockTools 1.5.6 [19]. The structures were saved in PDBQT format.

\subsection{Molecular docking study}

The binding affinity of each vitamin compound with the SARS-Cov-2 structural and non-structural targets was determined by molecular docking method. The molecular docking was performed using blind docking method in Autodock Vina 1.1.2 [20]. The grid box outsized enough to cover the entire protein structure to encounter any probable protein-ligand interactions. The binding poses were clustered and ranked in the order of their binding affinities. The molecular interactions (hydrogen bonds and hydrophobic interactions between the target proteins and compounds were studied using LigPlot + version 1.4.5 [21].

\subsection{Molecular dynamics simulation}

The $50 \mathrm{~ns}$ molecular dynamics (MD) simulation was carried out for complex using Gromacs version 5.1.1. [22] The simulation system was set up using the CHARMM-GUI web-based graphical interface [23]. The CHARMM General Force Field (CGenFF) program (University of Maryland, Baltimore, MD, USA) was used to create ligands and the CHARMM36m force field was used to construct the system. CGenFF is considering a partial atomic charge to create 
a ligand parameter (http://docs.silcsbio.com). Charges are set according to the mandatory charge increase scheme [24]. The protein-ligand system was dissolved in the aqueous TIP3P model and ionized with $\mathrm{NaCl}$. After the system is neutralized, energy minimization is carried out to eliminate steric collisions. This minimum energy system is balanced in six steps by gradually reducing the constant and thermal power (in the NVT ensemble) at $500 \mathrm{~K}$ and the pressure (in the NPT ensemble) at 1 bar per 1000 ps. Simulation results were first centered and trajectories analyzed with VMD software [25]. A variety of analytical methods are used for path analysis, including RMSD calculations, interaction energy calculations and many more.

\section{Results and discussion}

Vitamins are the essential elements required for cell proliferation, function and development. Moreover, it plays a crucial role against the pathogens via cell-mediated response and increase the immunity. All the vitamins except vitamin $\mathrm{C}$ are reported for the antibody production [26].

Till now, there is no specific antiviral therapy for COVID-19. However, drug repurposing has been an approach accepted by scientists to seek effective treatment in a short period [27]. Recent studies revealed that vitamins reduce the risk of pneumonia and other viral respiratory tract infections [28]. The vitamins also exhibit direct inhibition of viral replication or with immunomodulatory or anti-inflammatory means [29-31]. The computational approach, molecular docking appears as a tool for screening new antiviral compounds. Anywhere scientists can practice this tool as a complementary approach so the synthesis of new compounds or repositioning of drugs can be assigned.

The present computational study conducted to investigate structural characteristics and molecular details of interactions between the SARS-CoV-2 therapeutic targets and the supplementary drugs vitamins. This is not the first time that vitamins have been considered for a new medical use. Vitamins have been proposed as immunomodulators since time immemorial. Vitamins are essential nutrients as they serve a plethora of important metabolic functions in the body. It has been well documented that the protection provided by vitamins through the natural defence mechanism of the host not only functions against infectious diseases, but also against cancer and other degenerative diseases. The enhancement of host resistance to disease results due to biosynthetic, antioxidant and immunostimulatory activity. Direct antiviral action of some vitamins to protect against viral disease being inactivation of a wide spectrum of viruses as well as suppress viral replication and expression in infected cells. 
One mechanism of virus inactivation can be explained that depends on presence of oxygen and production of reactive oxygen species (ROS) through the Nrf 2 pathway [32]. COVIDassociated severe cases, the result of complex biological spectacles, such as apoptosis induction, macrophage activation, oxidative tissue damage and higher contents of proinflammatory cytokines [33]. The superoxide anion-mediated pathways denote severe tissue injury for that drug with antiviral and antioxidant activities may be the choice. Therefore, apart from Vita.C. we selected vitamins with antioxidant properties, Vita.A, Vita. E and Vita.D. Antioxidant properties of vitamin A, C, E and D are being utilized against heightening oxidative stress in COVID reatment [34, 35]. Moreover, Vita. D with its ACE2 binding property also being exploited against increased ACE2, resulted from demethylation by the virus activity [36]. Direct antiviral activity by remarkable binding of vitamins as inhibitors to various important proteins of SARS-Cov-2 are suggested in the present report.

\subsection{Molecular docking of vitamins with viral targets}

In this study, 15 vitamins (see supplementary table S1) were docked against five nonstructural proteins (NSP3, NSP5, ORF7a, NSP12 and ORF3a) and two structural proteins (Spike and Hemagglutinin esterase) and on one host protein furin. Since the presence of furin cleavage site (PRRA motif) in the spike has been confirmed [37], researchers are engaged in looking for a satisfactory mechanism to explain the importance of furin activity in spike maturation thus viral infectivity. Furin was shown to facilitate virus entry into the cell after receptor binding for other coronaviruses, e.g., MERS-CoV [38]. Furin is generally membrane bound, but an active isoform has been described that can be secreted, potentially facilitating cleavage of the SARS-CoV-2 S protein in the cellular neighbourhood [39]. Realising the important role of this host protease in spike activation we also targeted the protein for inhibitor binding that resulted with a very exciting outcome. The arrangement of the binding mode of the ligands is considered mainly based on the positions of hydrogen bond interaction with protein and minimum binding energy. Amongst all molecules vitamin B12, vitamin D3 and vitamin B9 exhibited good affinity, and vitamin B15 showed strong interaction in terms of $\mathrm{H}$ bonds. Table1 illustrates of binding energies of all vitamins with target protein of SARS-CoV2. 
Table 1: Binding energies of Covid-19 targets with Vitamins.

\begin{tabular}{|l|r|r|r|r|r|r|r|r|}
\hline & $\begin{array}{r}\text { Mpro } \\
\text { (NSP5) }\end{array}$ & \multicolumn{1}{l}{ RDRP } \\
(NSP12)
\end{tabular}

\subsubsection{Vitamin B}

The group of vitamin B has a prime role for the immune response to antigen as well some of the water-soluble vitamins act as a coenzyme in the body for certain biochemical reaction to enhance the immune system. Thiamine, also called Vitamin $\mathrm{B} 1$ has a role in $\mathrm{B}$ and $\mathrm{T}$ cell production [40]. Riboflavin (B2) in combination with UV hinders DNA replication in MERS $\mathrm{CoV}$. Hence it may have a role in SARS- CoV prevention. Nicotinamide (V-B3) is the building block of NAD+, which acts as a coenzyme in various metabolic pathways. Hence, it plays a significant role in the inflammatory response and prevents lung tissue damage. Pyridoxal 5'phosphate is the active form of vitamin B6 and is involved in carbohydrate, protein and lipid metabolism. BAN (vitamin B6-derived bananin) inhibits the SARS-helicase enzyme, which hinders the viral replication process. Vitamins B6, B12, and B9 (folic acid) proliferate the 
activity of natural killer cells, which offers a significant antiviral effect. Vitamin B12 inhibits the RNA-dependent RNA polymerase, which leads to the SARS-CoV-2 viral replication. In a nutshell, vitamin B complexes have the potential to frontier the complications associated with COVID-19 infection [41].

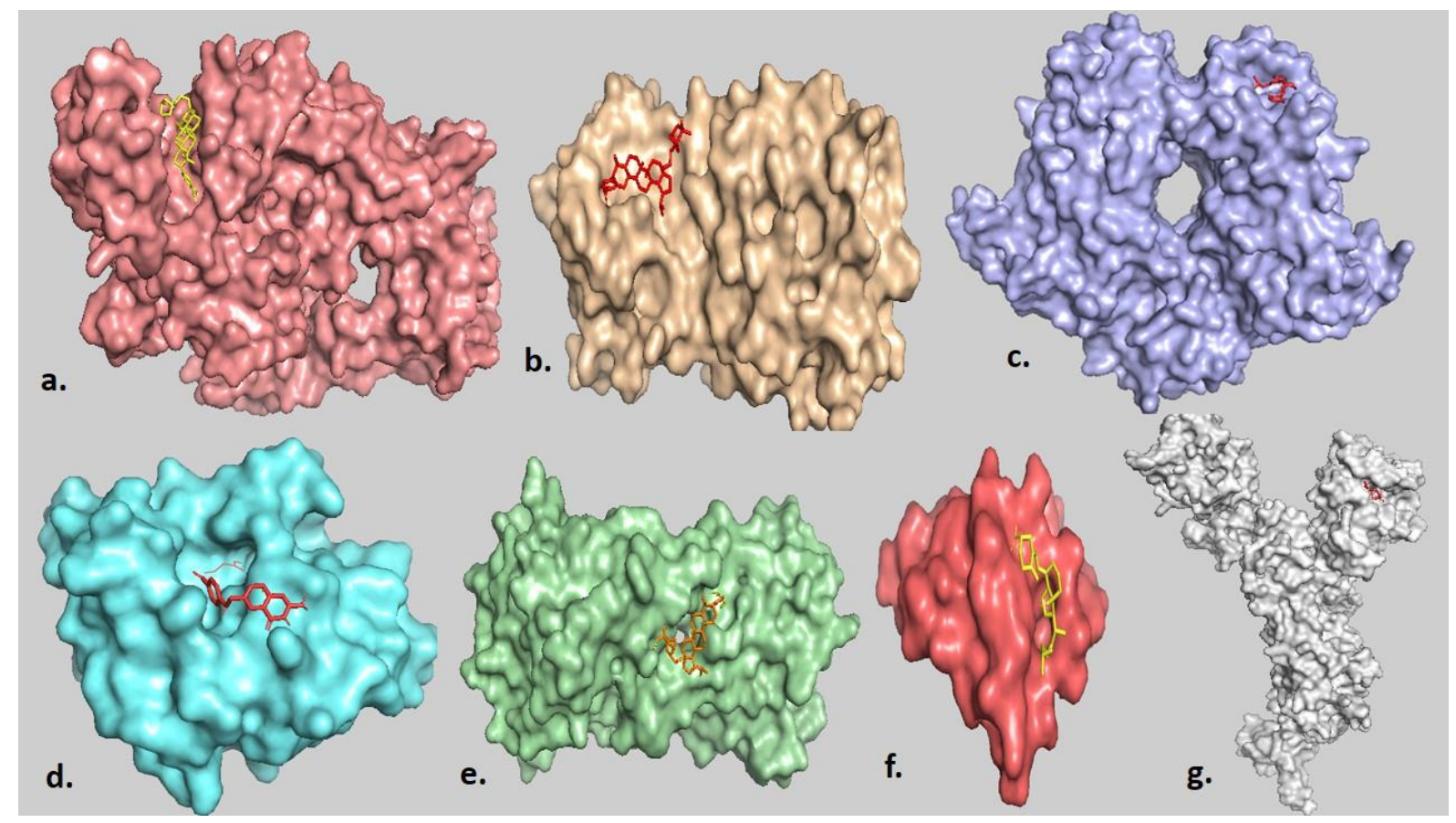

Figure 1: Top molecular interaction of SARS-CoV-2 Drug targets and vitamin: (a) RdRPVita.B12. (b) MPro-Vita.b12. (c) HE-Vita.D3. (d) NSP3-Vita.B9 (e) ORF3a-Vita.B12 (f) ORF7a-Vita.B12. (g) Spike-Vita.D3.

Our results reveal that vitamin B12 is an efficient nutraceutical for almost all the nCoV-2 drug targets including the host protease furin. Methylcobalamin unveiled high binding affinity with furin $(-9.2 \mathrm{kcal} / \mathrm{mol}), \operatorname{RdRP}(-8.0 \mathrm{kcal} / \mathrm{mol}), \mathrm{HE}(-9.0 \mathrm{kcal} / \mathrm{mol}), \mathrm{NSP} 5(-7.3 \mathrm{kcal} / \mathrm{mol}) \mathrm{NSP} 3$ (-6.9 $\mathrm{kcal} / \mathrm{mol})$, ORF7a $(-6.1 \mathrm{kcal} / \mathrm{mol})$, ORF3b $(-6.9 \mathrm{kcal} / \mathrm{mol})$ proteins. However, the spike protein of nCOV-2 defended and demonstrated zero binding affinity with this vitamin. In this study, Vita.B12 exemplify fair interaction with furin in terms of seven H-bonds and nine hydrophobic interactions. The interacting residues of furin in context to H-bonds and

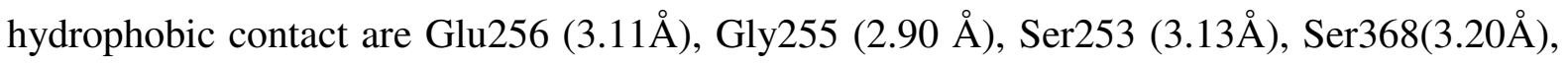

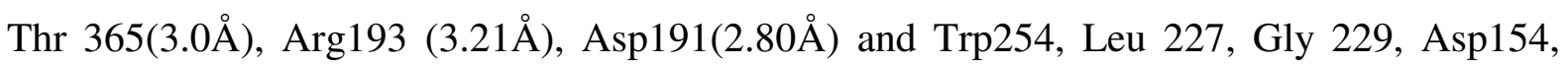
Asn190, His 364, His 194, Asn295, Asp258 respectively ( see figure 2).

Vita.B12 also shows good hydrophobic interactions with 15 amino acids (leu172, phe169, asp170, arg173, arg249, thr319, tyr265, phe321, pro323, arg349, phe396, thr394, leu 
460, pro667, pro461) and four H-bonds tyr465 (3.19 ̊). Asn459 (3.15 ̊̊), cys395 (2.95 $)$, $\arg 415(2.80 \AA)$ with RNA dependant RNA polymerase enzyme. Figure 3 shows that Vita.B12 has decent interactions with all viral targets.

Vitamin B12, cobalamin, is a water-soluble vitamin produced in nature by microorganisms mainly get from animal proteins and deficiency cause with different disease states [42]. It is involved in different pathways as well in hematopoiesis. B12 is an important factor for activation of transcription factors like NF-kB, Myc and Fos [43] and thought to potentiate anti-inflammatory effects. Though Vita.B12 has been used to improve immunity in HIV infected patients, there is no evidence of direct inactivation of any virus by this compound.

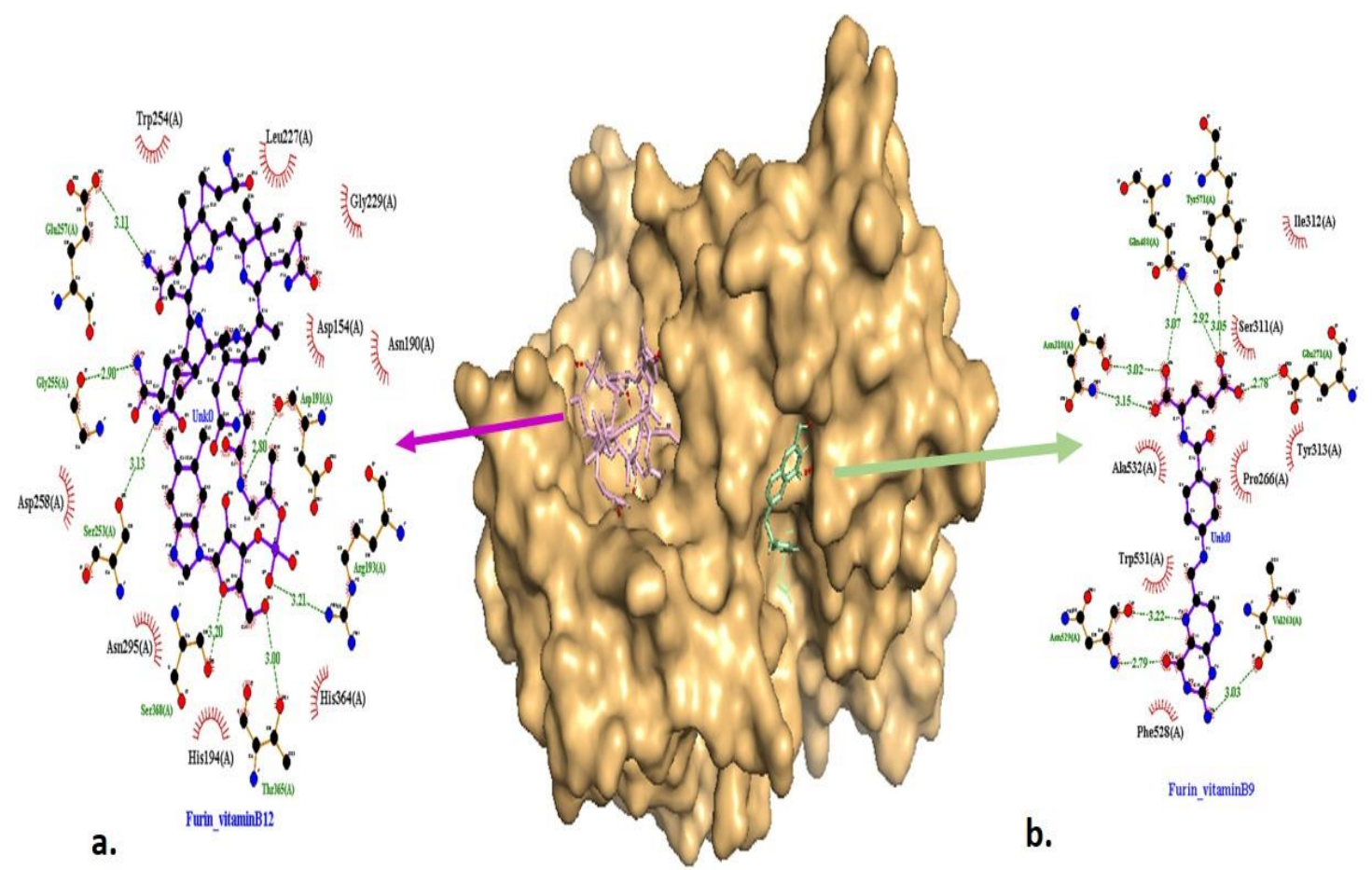

Figure 2: Interaction of furin residues with (a) vitamin B12 and (b) vitamin B9.

The insilico analysis explained that vitamin B9 proved one of the best inhibitor for all viral targets. Amongst eight viral targets Vita.B9 illustrates best binding with Furin $(-8.2 \mathrm{kcal} / \mathrm{mol})$, spike (-7.4 kcal/mol), RdRp (-7.6 kcal/mol), NSP3 proteins (-7.6 kcal/mol) (See Fig.3.). Our frequent observation denotes (Fig.2.) that amino acids residues of furin interrelates with vitamin B9 and vitamin B12 at distinguished domains. LigPlot exposed two strong H-bonds

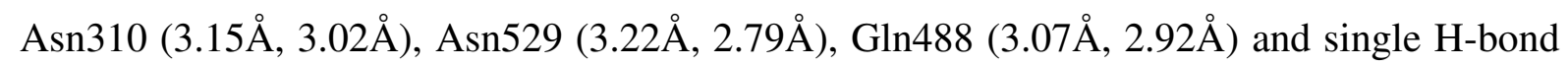

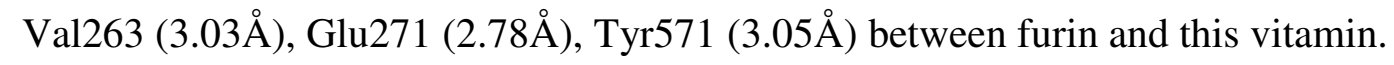




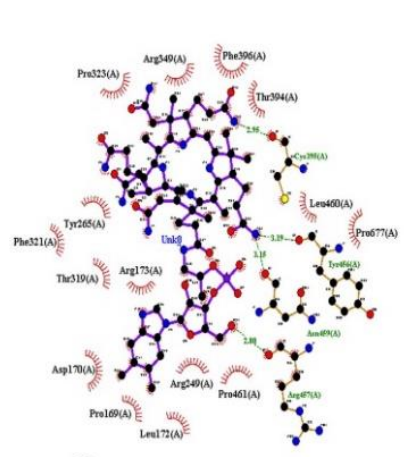

a.

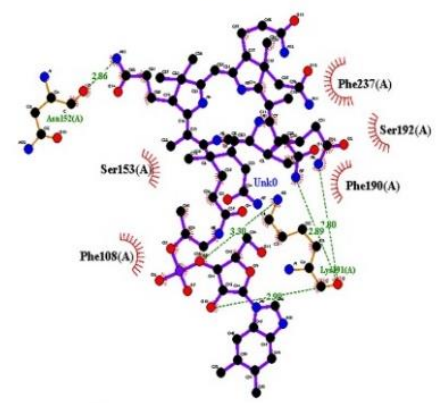

d. HL- Hutumbin

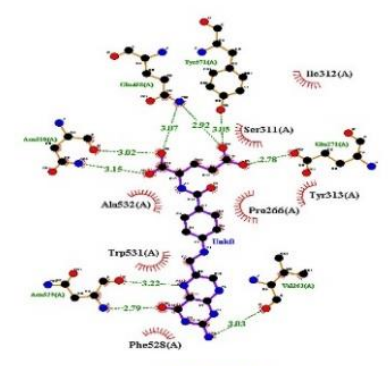

g.

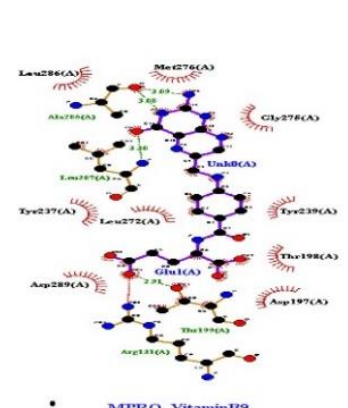

j.

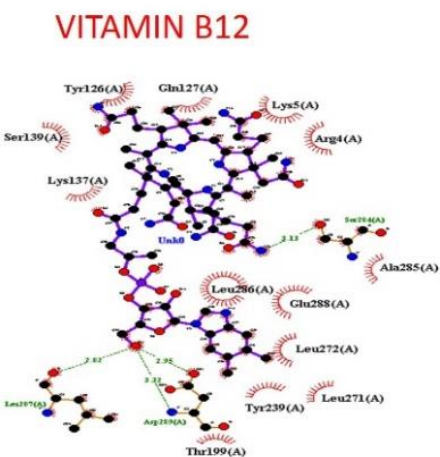

b. мево_nnamingrz

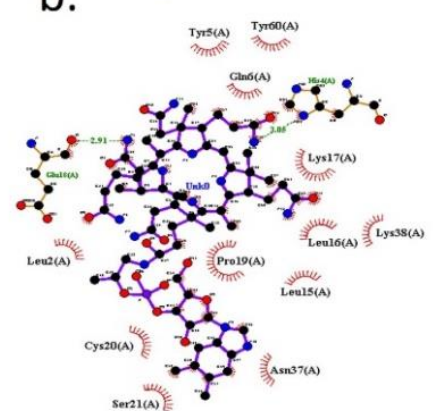

e.

\section{VITAMIN B9}

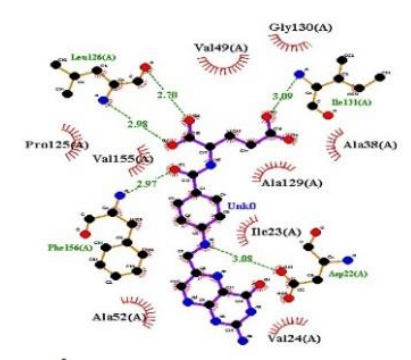

h. Nsp3_-ntamming

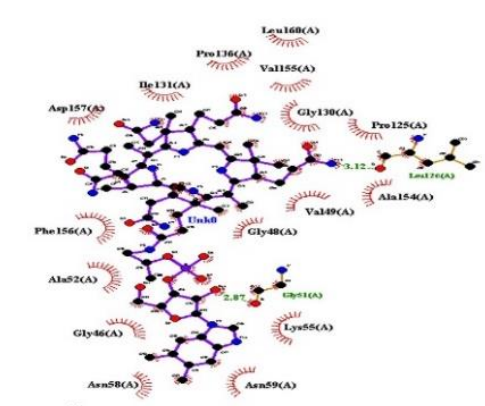

C.

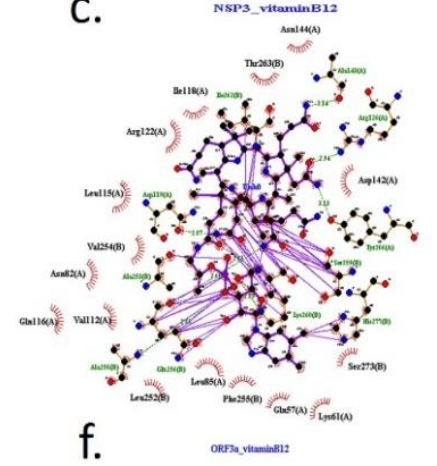

f.

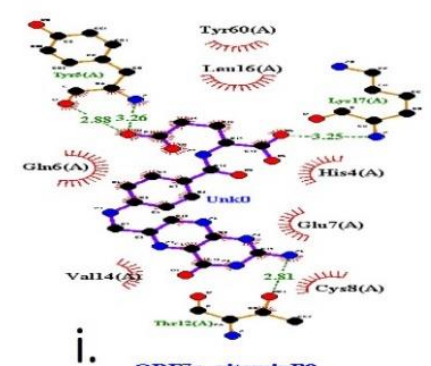

Figure 3: Interaction plot of vitaminB12 and vitamin $B 9$ with all viral targets. (a) RDRPVita.B12. (b) MPRO-Vita.B12. (c) NSP3-Vita.B12. (d) HA-Vita.B12. (e) Orf7a-Vita.B12. (f) Orf3a-Vita.B12. (g) Furin-Vita.B9. (h) NSP3-Vita.B9. (i) Orf7a-Vita.B9. (j) MPRO-Vita.B9. (k) HA-Vita.B9. (l) RDRP-Vita.B9. (m) Orf3a-Vita.B9. 
Vitamin B9, Folic acid is a type of B vitamin normally found in foods rich in iron and dried beans mainly helps the body to produce and maintain new cells, DNA repair mechanism. It is well known that folate intake is essential for human health because it prevents megaloblastic anaemia and neural tube birth defects as well as cardiovascular disease, dementia, cognitive function alterations, osteoporosis and several types of cancer. Recent computer simulation researches on antiviral activity of Vita.B9 have been reported [44, 45] where the authors have suggested that B9 can inactivate the furin endoprotease that is crucial for the SARS-CoV-2 virus to enter its host cell [46, 47]. While another work [48] explained that Vita.B9 inactivates protease $3 \mathrm{CL}^{\text {pro }}$, which is vital in the replication of all coronaviruses.

The structure of the vitamin B15 also known as pangamic acid complexed with HE protein, ORF7a, NSP5 and NSP12 highlighted hydrogen bond interaction to be the main contributor in protein-ligand interaction whereas binding energy contributes moderately (Fig.3.) in this study. This vitamin shows maximum15 H-bond interaction with viral HE protein, $10 \mathrm{H}$-bonds with ORF7a and 7 with NSP5. It is reported that assorted strong-weak Hbond unions decrease ligand binding affinity and sometimes connects poorly with experimental binding affinity [49]. The robust hydrogen bonding and hydrophobic interaction between vitamin with the enzyme infer it may be a potent HE and ORF7a inhibitor.

Laboratory experiments have proven the protective effect of B15 on coronary artery occlusion and myocarditis in animals. Though controversy exists in categorising B15 under vitamin group it has received the most attention for its effect in stress and on athletic and physical effort. Apart from its protective role in hypoxia, another important function of cellular detoxification associated with cytochrome p450, B15 has a protective role in various health conditions like fatty infiltration of liver, atherosclerosis, alcoholism etc [50]. Anticipating its role in covid-19 induced hypoxia the present investigation also focused on its antiviral activity. Amongst Vita.B1 to B6, Vita.B2, B5, and B6 manifest good H-bond networks with all viral targets (Fig.S1 \& S2). Our results unveil zero affinity of Vita.B1 and B2 and no interaction with spike protein. In contrast to that, Vita.B3, B5, and B6 have connections with S protein. Vita.B5 shows a maximum of $8 \mathrm{H}$-bonds with $\mathrm{S}$ protein and $7 \mathrm{H}$-bonds with furin.

\subsubsection{Vitamin D3}

The authors of the present report are able to find a mechanism through binding of vita. D3 to various proteins of nCov-2. The vitamin D3 displays best dock score with furin $(-8.2$ $\mathrm{kcal} / \mathrm{mol}), \operatorname{RdRP}(-7.4 \mathrm{kcal} / \mathrm{mol}), \mathrm{HE}(-8.1 \mathrm{kcal} / \mathrm{mol}), \mathrm{NSP} 3$ (-7.6 kacal/mol), spike protein (- 
$7.4 \mathrm{kcal} / \mathrm{mol})$, ORF7a $(-6.1 \mathrm{kcal} / \mathrm{mol})$, ORF3b $(-6.9 \mathrm{kcal} / \mathrm{mol})$ proteins. In this study, we observed that all viral targets spectacles (Fig. 4) decent hydrophobic interactions with vitamins. Klebe in 2015 reported that binding affinity of several ligands is very high due to hydrophobic interactions. In hydrophopic intractions, ligand suppresses the lipophilic surface of target protein and dislocates the water.

Vitamin D from diet and dietary supplements is converted to its biologically active form inside the human body. Photo-mediated conversion of 7- dehydrocholesterol in the skin is the primary source of Vita.D inside our body. Thus exposure to sunlight is important to promote vitamin D production in the skin. Major sources of Vita.D include egg yolks, saltwater oily fish and liver as food. Some other foods, like milk and cereal, mushrooms often have added vitamin D. To become biologically active D3, 25-hydroxylation of vitamin D requires in the liver and subsequent 1-hydroxylation in the kidney [51]. The fat soluble Vita.D plays a central role in calcium and phosphate homeostasis that is essential for the proper development and maintenance of bone. It is also involved in cell proliferation, differentiation, and immunomodulation. Vitamin D deficiency is associated with increased risk of viral infections such as influenza, respiratory tract infections, and human immunodeficiency virus (HIV) along with many pathological conditions, including cancer, autoimmune diseases, cardiovascular disease, and diabetes [52,53] reported the reason for antiviral activity of Vita.D3 in HCV to be the increased expression of interferon. In the context of increasing respiratory tract infection cases of COVID-19 patients a host of authors are suggesting the Vita.D to be the wonder drug for cure. However, a proper mechanism to confirm the role of Vita.D is lacking.

\subsubsection{Vitamin C}

Vitamin C (ascorbic acid) essentially required as a natural antioxidant in the body for correct functioning of the immune system, it's a great immunity booster compare to all vitamins found in nature due to its antioxidative property. Thus, it shows potentiality against various infections, including coronavirus infections [53]. Its role in stress response after administration in critically ill COVID-19 patients is well documented. To understand the mechanism of Vita.C, structural and non-structural n-Cov2 proteins were analysed. The ligand interaction maps of the compound with best dock conformation reported in supplementary figure S3. This computational study ascertains inhibitory effect of ascorbic acid on all viral protein. Vita.C indicates (Supplementary Figure S3) interactions with furin, RdRp, ORF7a and HE proteins. 


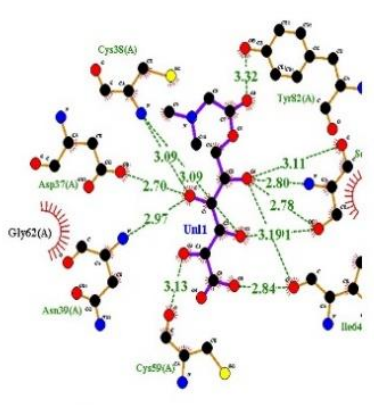

a. HA_VitaminB15

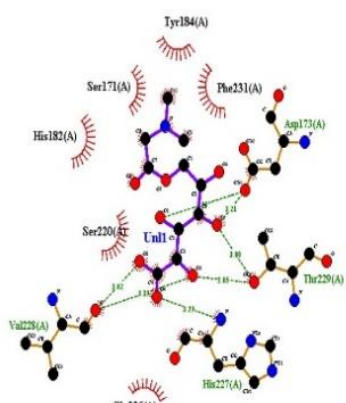

e. or[3a vitaminB15

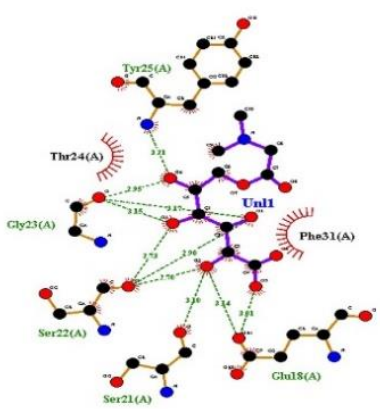

b.

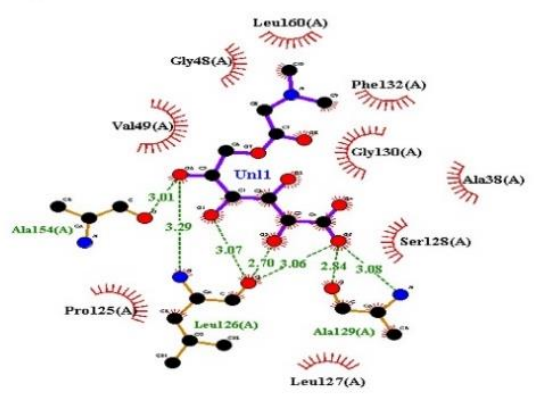

f. NSP3_vitaminB15

VITAMIN D3

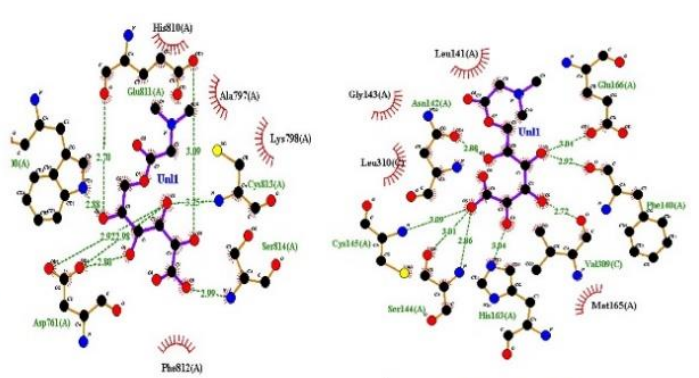

d. MPRO_VtaminB15

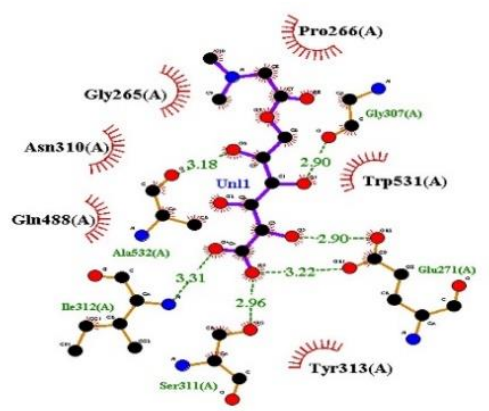

g. Furin_vitaminB15
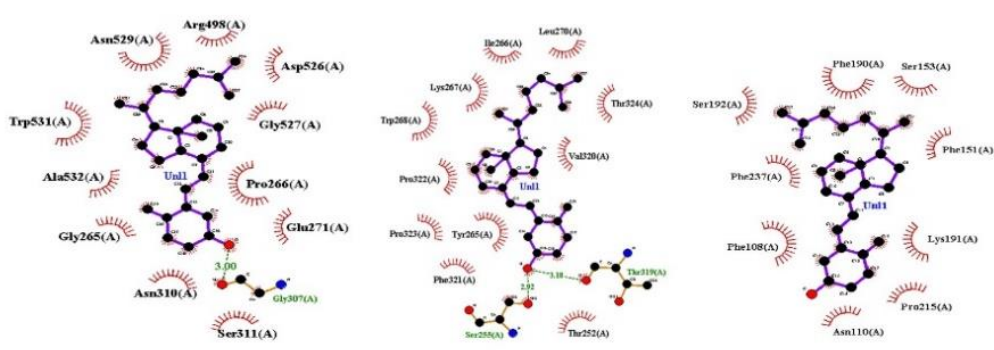

h. Furin vitaminds$$
\text { i. }
$$

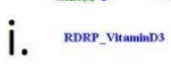

$\mathrm{j}$

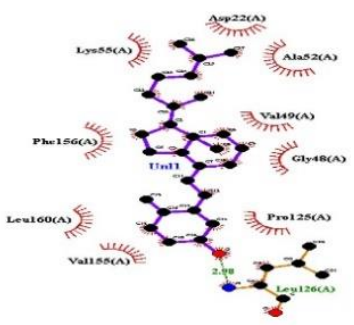

k.
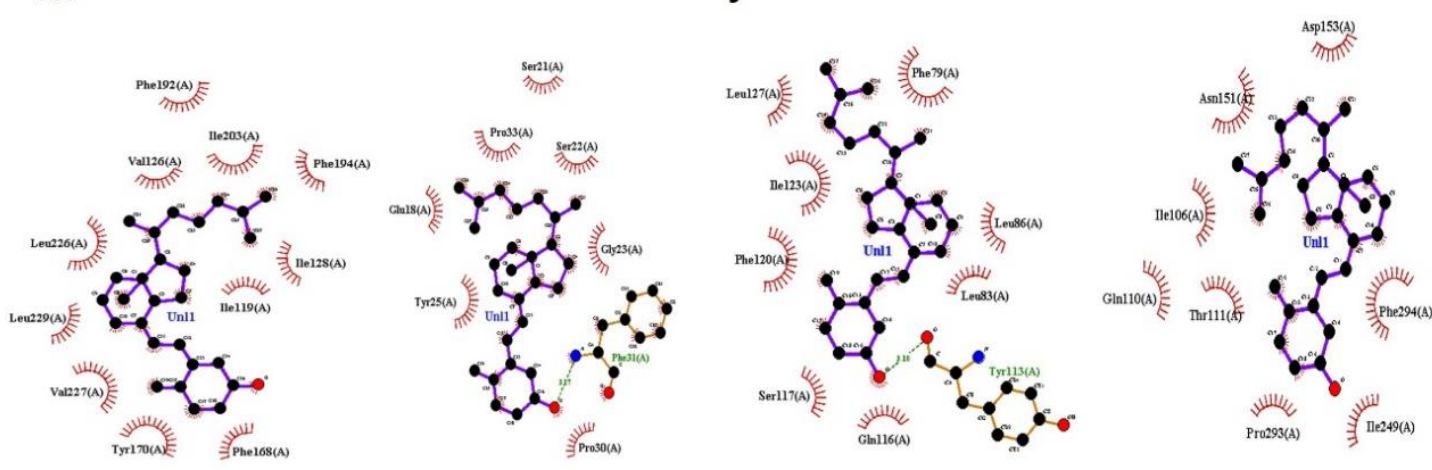

I. SPIKE_vitaminD3

M. orfa_ vitaminD3

O. MPRO_VitaminD3

Figure 4: Interaction plot of vitaminB15 and vitamin D3 with COVID-19 targets. (a) HAVita.B15. (b) Orf7a-Vita.B15. (c) RDRP-Vita.B15. (d) MPRO-Vita.B15. (e) Orf3a-Vita.B15. (f) NSP3-Vita.B15. (g) Furin-Vita.B15. (h) Furin-Vita.D3. (i) RDRP-Vita.D3. (j) HAVita.D3. (k) NSP3-Vita.D3. (l) SPIKE-Vita.D3. (m) Or7a-Vita.D3. (n) Orf3a-Vita.D3. (o) MPRO- Vita.D3. 
Viral infections generate oxidative stress and certain redox-active substances such as antiviral drug are expected to suppress oxidative stress improve inflammatory symptoms. Influential scavenging and antioxidative property of ascorbic acid have shown protective effect [54]. Both in vitro and in vivo clinical trials with Vita.C treatments showed significant reduction of viral replication without any insight to proper inhibitory mechanisms [55]. The present investigation may be for the first time able to find a plausible mechanism from the observed binding properties to the viral proteins.

\subsubsection{Vitamin K}

Fat-soluble vitamin $\mathrm{K}$ primly affects blood clotting along with wound healing as well as modulate the calcium-binding in bones. Vitamin K deficiency reported a poor outcome of COVID-19 [56]. The ligand interaction plot (supplementary Fig.S4.) displays more number of hydrophobic interactions with both vitamin K1 and K2. Vita.K1 shows good docking score with one target ORF7a $(-7.2 \mathrm{kcal} / \mathrm{mol})$ and vitamin $\mathrm{K} 2$ displays $-7.1 \mathrm{kcal} / \mathrm{mol}$ affinity with NSP3 and furin.

\subsubsection{Vitamin E}

Vitamin E deficiency has shown increased levels of the viral (coxsackievirus B3) infection end up with a myocardial injury in mice, due to oxidative stress [57]. Likewise, vitamin E deficiency in calves was associated with a high risk of bovine coronavirus infection [31] Vita.E known as Alpha -tocopherol shows fair score -7.5,-7.2 and $-6.6 \mathrm{kcal} / \mathrm{mol}$ with furin, $\mathrm{HE}$ proteins and NSP3 one-to-one.

\subsubsection{Vitamin A}

Vitamin A plays a key role for the normal eye vision, functional immune system, and for reproduction. Furthermore, it regulates the antigen-presenting cells and maintains the balance between Th1 and Th2 lymphocytes and produces an antibody response against an antigen [58]. Hence, it is the most promising vitamin against lung damage due to COVID-19. The structural protein spike and $\mathrm{HE}$ protein of $\mathrm{nCOV}-2$ reveal robust interaction results with Vita.A (Fig.S3.).

\subsection{Molecular dynamics simulation of Furin and Vitamin B12}

The MD simulation on best docking score complex (Furin-Vitamin B12) for 50 ns measure up to examine the dynamic performance of the protein-ligand complex. The structure experienced initial fluctuation due to the kinetic shock applied during the MD simulation. Figure 5 shows the graphical representation of the root means square deviation (RMSD) and root means square fluctuation (RMSF) of the complex in each amino acid. The amino acid in complex with 
vitamin B12 maintains equilibrium throughout the simulation. Around $\sim 0.2 \mathrm{~nm}$ RMSD was reported for backbone atoms of the ligand-protein complex. The complex re-equilibrated a few times during the $50 \mathrm{~ns}$ simulation. Figure 5a illustrates the retreating of the ligand orientation near $\sim 15 \mathrm{~ns}$ and $\sim 30 \mathrm{~ns}$. The magnitude of fluctuation and the difference between the average RMSD values recommended that simulation produced stable trajectories.

RMSD

a.

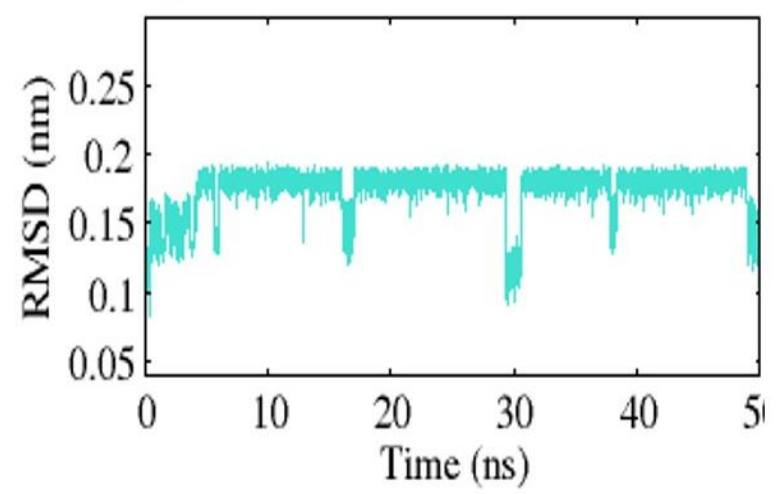

RMS fluctuation

b.

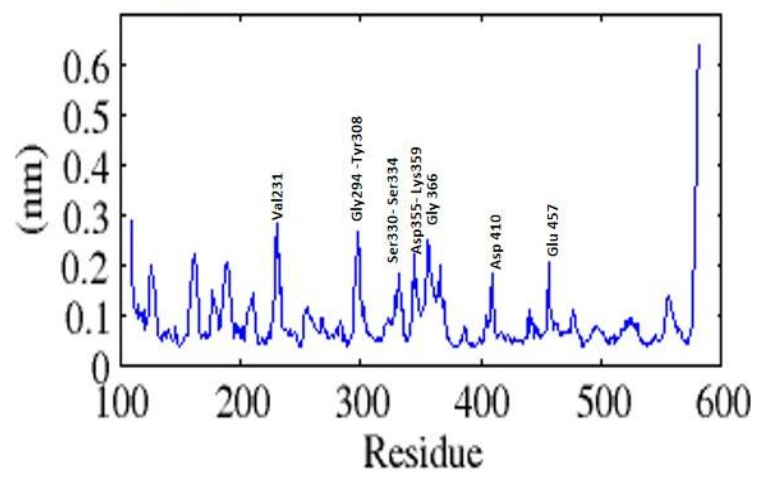

Figure 5: (a.) RMSD and (b.) RMSF trajectory of Furin-Vitamin B12 complexes obtained from 50 ns $M D$ simulation.

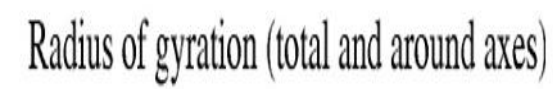

a.

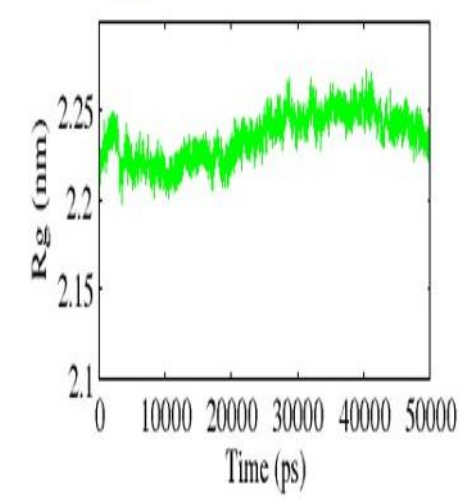

GROMACS Energies

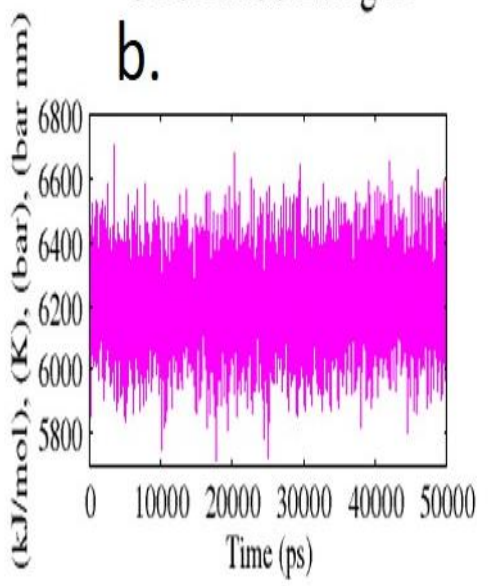

Solvent Accessible Surface

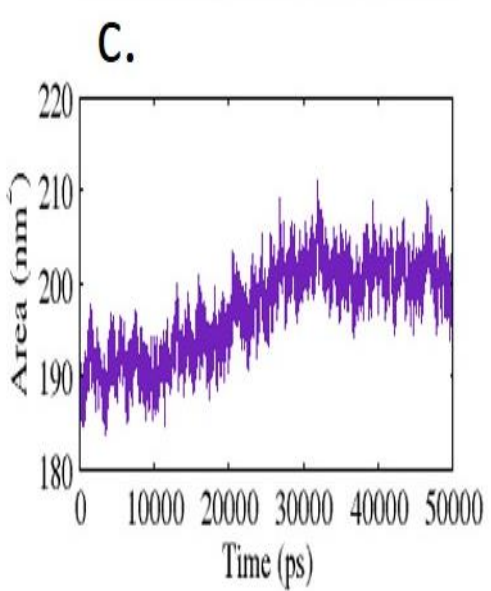

Figure 6: $M D$ trajectories for (a) Radius of gyration (b) potential energy (C) Solvent accessible surface area. 
The RMSF analysis correlates with the functional analysis and the highest fluctuation in this region. These reported decrease in scores of particular residues proposes their direct participation in enhancing the overall stability of the bound protein complex. The amino acid residues 250, 300, and 350-375 showed high fluctuation. The fluctuation in amino acids is Val $231(\sim 0.2 \mathrm{~nm})$, Gly 294 to Tyr308 ( 0.12 - $\sim 0.24 \mathrm{~nm})$. The radius of gyration $(\mathrm{Rg})$ is defined as the circulation of atoms of a protein around its axis. The radius of gyration Furin-Vitamin B12 complex is $\sim 2.2$ to $\sim 2.25 \mathrm{~nm}$. The length signifies the distance between the point of rotation and the point where the transfer of energy has the extreme effect gives $\operatorname{Rg}$ [59]. The $\operatorname{Rg}$ qualifies one to assess the compactness changes of a ligand-protein complex.

The potential energy scrutinized during the $50 \mathrm{~ns}$ molecular dynamics simulations is shown in figure 6(b). The potential energy graph shows that all the molecular system stabilized and remained stable throughout the simulations. The variations in the solventaccessible surface area (SASA) of a protein specifies the change in exposed amino acid residues could affect the tertiary structure of proteins [60]. Protein-ligand complex exhibited SASA $\sim 190-200 \mathrm{~nm}$ square in the dynamic period of $\sim 10-30 \mathrm{~ns}$ (Fig.6c.). After the period of $30 \mathrm{~ns}$, the complex exhibited a very high-solvent accessible area. This type of illustration in an experimental setup will be time-consuming, thus creating a method for computational microscope MD to analyze the structural effects [61-63]. The molecular dynamics study of the best ligand-receptor complex also exhibits the stability of the compound during the simulation process, which validates the virtual screening and docking results.

\section{Conclusion}

In order to tackle the current situation, quick discovery of new antivirals is necessary which may be a resource from the extensive exiting research and development efforts. The present study revealed that the role of vitamins as immunonutritions could be deployed as potential supplements to attenuate the severity of the covid19 infection.

Contribution of authors: The conception and design of study by JD, MP, KJ. Acquisition of data, analysis and interpretation DM, TJ, AP, AG \& MP. Drafting and revising article by SS, JD \& KJ.

Ackowledgment: The authors would like to thank COVID-19 Omics Research Consortium (CORC) for providing this platform. 


\section{References:}

1) Wu, C., Zheng, M., Yang, Y., Gu, X., Yang, K., Li, M., ... \& Wang, Q. (2020). Furin: A Potential Therapeutic Target for COVID-19. Iscience, 23(10), 101642.

2) Guarner, J. (2020). Three emerging coronaviruses in two decades: the story of SARS, MERS, and now COVID-19, 420-421.

3) Chen, Y., Liu, Q., \&Guo, D. (2020). Emerging coronaviruses: genome structure, replication, and pathogenesis. Journal of medical virology, 92(4), 418-423.

4) Fung, S. Y., Yuen, K. S., Ye, Z. W., Chan, C. P., \& Jin, D. Y. (2020). A tug-of-war between severe acute respiratory syndrome coronavirus 2 and host antiviral defence: lessons from other pathogenic viruses. Emerging microbes \& infections, 9(1), 558-570.

5) De Wit, E., Van Doremalen, N., Falzarano, D., \& Munster, V. J. (2016). SARS and MERS: recent insights into emerging coronaviruses. Nature Reviews Microbiology, 14(8), 523.

6) Ou, X., Liu, Y., Lei, X., Li, P., Mi, D., Ren, L., ... \& Xiang, Z. (2020). Characterization of spike glycoprotein of SARS-CoV-2 on virus entry and its immune cross-reactivity with SARS-CoV. Nature communications, 11(1), 1-12.

7) J Alsaadi, E. A., \& Jones, I. M. (2019). Membrane binding proteins of coronaviruses. Future Virology, 14(4), 275-286.

8) Lu, R., Zhao, X., Li, J., Niu, P., Yang, B., Wu, H., ... \& Bi, Y. (2020). Genomic characterisation and epidemiology of 2019 novel coronavirus: implications for virus origins and receptor binding. The Lancet, 395(10224), 565-574.

9) Kumar, V., \& Jena, M. (2020). In silico virtual screening-based study of nutraceuticals predicts the therapeutic potentials of folic acid and its derivatives against COVID-19.

10) Wu, C., Chen, X., Cai, Y., Zhou, X., Xu, S., Huang, H., .. \& Song, J. (2020). Risk factors associated with acute respiratory distress syndrome and death in patients with coronavirus disease 2019 pneumonia in Wuhan, China. JAMA internal medicine.

11) Scavone, C., Brusco, S., Bertini, M., Sportiello, L., Rafaniello, C., Zoccoli, A., ... \& Capuano, A. (2020). Current pharmacological treatments for COVID- 19: What's next?. British Journal of Pharmacology.

12) Guo, Y. R., Cao, Q. D., Hong, Z. S., Tan, Y. Y., Chen, S. D., Jin, H. J., ... \& Yan, Y. (2020). The origin, transmission and clinical therapies on coronavirus disease 2019 (COVID-19) outbreak-an update on the status. Military Medical Research, 7(1), 1-10. 
13) Bhoyar, R. C., Jain, A., Sehgal, P., Divakar, M. K., Sharma, D., Imran, M., ... \& Siwach, S. (2020). High throughput detection and genetic epidemiology of SARSCoV-2 using COVIDSeq next generation sequencing. bioRxiv.

14) Lata, K. S., Vaghasia, V., Bhairappanvar, S., Patel, S., \& Das, J. (2020). Vaccine Design Against Leptospirosis Using an Immunoinformatic Approach. In Immunoinformatics, Humana, New York, NY, 173-184.

15) Bloise, E., Zhang, J., Nakpu, J., Hamada, H., Dunk, C. E., Li, S., ... \& Matthews, S. G. (2020). Expression of severe acute respiratory syndrome coronavirus 2 cell entry genes, angiotensin-converting enzyme 2 and transmembrane protease serine 2 , in the placenta across gestation and at the maternal-fetal interface in pregnancies complicated by preterm birth or preeclampsia. American Journal of Obstetrics and Gynecology.

16) Baladia, E., Pizarro, A. B., \& Rada, G. (2020). Vitamin C for the treatment of COVID19: A living systematic review. medRxiv.

17) dos Santos, L. M. J. (2020). Can vitamin B12 be an adjuvant to COVID-19 treatment?. GSC Biological and Pharmaceutical Sciences, 11(3), 001-005.

18) Doboszewska, U., Wlaź, P., Nowak, G., \& Młyniec, K. (2020). Targeting zinc metalloenzymes in COVID- 19. British journal of pharmacology.

19) Morris, G. M., Huey, R., Lindstrom, W., Sanner, M. F., Belew, R. K., Goodsell, D. S., \& Olson, A. J. (2009). AutoDock4 and AutoDockTools4: Automated docking with selective receptor flexibility. Journal of computational chemistry, 30(16), 2785-2791.

20) Trott, O., \& Olson, A. J. (2010). AutoDock Vina: improving the speed and accuracy of docking with a new scoring function, efficient optimization, and multithreading. Journal of computational chemistry, 31(2), 455-461.

21) Laskowski, R. A., \& Swindells, M. B. (2011). LigPlot+: multiple ligand-protein interaction diagrams for drug discovery.

22) Abraham, M. J., Murtola, T., Schulz, R., Páll, S., Smith, J. C., Hess, B., \& Lindahl, E. (2015). GROMACS: High performance molecular simulations through multi-level parallelism from laptops to supercomputers. SoftwareX, 1, 19-25.

23) Jo, S., Kim, T., Iyer, V. G., \& Im, W. (2008). CHARMM- GUI: a web- based graphical user interface for CHARMM. Journal of computational chemistry, 29(11), 1859-1865.

24) Vanommeslaeghe, K., \& MacKerell Jr, A. D. (2012). Automation of the CHARMM General Force Field (CGenFF) I: bond perception and atom typing. Journal of chemical information and modeling, 52(12), 3144-3154. 
25) Humphrey, W., Dalke, A., \& Schulten, K. (1996). VMD: visual molecular dynamics. Journal of molecular graphics, 14(1), 33-38.

26) Aslam, M. F., Majeed, S., Aslam, S., \& Irfan, J. A. (2017). Vitamins: Key role players in boosting up immune response-A mini review. Vitam. Miner, 6, 153.

27) Rodríguez-Baño, J., Pachón, J., Carratalà, J., Ryan, P., Jarrín, I., Yllescas, M., ... \& Muñiz, P. G. (2020). Treatment with tocilizumab or corticosteroids for COVID-19 patients with hyperinflammatory state: a multicentre cohort study (SAM-COVID19). Clinical Microbiology and Infection.

28) Mohapatra, R. K., Pintilie, L., Kandi, V., Sarangi, A. K., Das, D., Sahu, R., \& Perekhoda, L. (2020). The recent challenges of highly contagious COVID-19, causing respiratory infections: Symptoms, diagnosis, transmission, possible vaccines, animal models, and immunotherapy. Chemical Biology \& Drug Design.

29) Ali, N. (2020). Role of vitamin D in preventing of COVID-19 infection, progression and severity. Journal of infection and public health .

30) Shakoor, H., Feehan, J., Mikkelsen, K., Al Dhaheri, A. S., Ali, H. I., Platat, C., ... \& Apostolopoulos, V. (2020). Be well: A potential role for vitamin B in COVID19. Maturitas.

31) Butt, H., Mehmood, A., Ali, M., Tasneem, S., Anjum, M. S., Tarar, M. N., ... \& Riazuddin, S. (2017). Protective role of vitamin E preconditioning of human dermal fibroblasts against thermal stress in vitro. Life sciences, 184, 1-9.

32) Schwarz, N., \& Clore, G. L. (1996). Feelings and phenomenal experiences.

33) Merad, M., \& Martin, J. C. (2020). Pathological inflammation in patients with COVID19: a key role for monocytes and macrophages. Nature Reviews Immunology, 1-8.

34) Munshi, R., Hussein, M. H., Toraih, E. A., Elshazli, R. M., Jardak, C., Sultana, N., ... \& Killackey, M. (2020). Vitamin D insufficiency as a potential culprit in critical COVID- 19 patients. Journal of medical virology.

35) Paredes, S., Girona, J., Hurt-Camejo, E., Vallvé, J. C., Olivé, S., Heras, M., ... \& Masana, L. (2002). Antioxidant vitamins and lipid peroxidation in patients with rheumatoid arthritis: association with inflammatory markers. The Journal of Rheumatology, 29(11), 2271-2277.

36) Rhodes, J. M., Subramanian, S., Laird, E., Griffin, G., \& Kenny, R. A. (2020). Perspective: Vitamin D deficiency and COVID- 19 severity-plausibly linked by latitude, ethnicity, impacts on cytokines, ACE2 and thrombosis. Journal of internal medicine. 
37) Coutard, B., Valle, C., de Lamballerie, X., Canard, B., Seidah, N. G., \& Decroly, E. (2020). The spike glycoprotein of the new coronavirus 2019-nCoV contains a furinlike cleavage site absent in $\mathrm{CoV}$ of the same clade. Antiviral research, 176, 104742.

38) Faridi, U. (2018). Middle East respiratory syndrome coronavirus (MERS-CoV): impact on Saudi Arabia, 2015. Saudi journal of biological sciences, 25(7), 1402-1405.

39) Lukassen, S., Chua, R. L., Trefzer, T., Kahn, N. C., Schneider, M. A., Muley, T., ... \& Hennig, B. P. (2020). SARS- CoV- 2 receptor ACE 2 and TMPRSS 2 are primarily expressed in bronchial transient secretory cells. The EMBO journal, 39(10), e105114.

40) Hirata, S. I., Sawane, K., Adachi, J., Isoyama, J., Sugiura, Y., Matsunaga, A., ... \& Kunisawa, J. (2020). Vitamin B1 supports the differentiation of T cells through TGF$\beta$ superfamily production in thymic stromal cells. Iscience, 23(9), 101426.

41) Junaid, K., Ejaz, H., Abdalla, A. E., Abosalif, K. O., Ullah, M. I., Yasmeen, H., ... \& Rehman, A. (2020). Effective immune functions of micronutrients against Sars-Cov2. Nutrients, 12(10), 2992.

42) Romain, M., Sviri, S., Linton, D. M., Stav, I., \& van Heerden, P. V. (2016). The role of Vitamin B12 in the critically ill—a review. Anaesthesia and intensive care, 44(4), 447-452.

43) Suarez-Moreira, E., Yun, J., Birch, C. S., Williams, J. H., McCaddon, A., \& Brasch, N. E. (2009). Vitamin B12 and redox homeostasis: cob (II) alamin reacts with superoxide at rates approaching superoxide dismutase (SOD). Journal of the American Chemical Society, 131(42), 15078-15079.

44) Sheybani, Z., Dokoohaki, M. H., Negahdaripour, M., Dehdashti, M., Zolghadr, H., Moghadami, M., ... \& Zolghadr, A. R. (2020). The role of folic acid in the management of respiratory disease caused by COVID-19.

45) Braun, E., \& Sauter, D. (2019). Furin- mediated protein processing in infectious diseases and cancer. Clinical \& translational immunology, 8(8), e1073.

46) Coutard, B., Valle, C., de Lamballerie, X., Canard, B., Seidah, N. G., \& Decroly, E. (2020). The spike glycoprotein of the new coronavirus 2019-nCoV contains a furinlike cleavage site absent in CoV of the same clade. Antiviral research, 176, 104742.

47) Wu, C., Zheng, M., Yang, Y., Gu, X., Yang, K., Li, M., ... \& Wang, Q. (2020). Furin: A Potential Therapeutic Target for COVID-19. Iscience, 23(10), 101642.

48) Jovic, T. H., Ali, S. R., Ibrahim, N., Jessop, Z. M., Tarassoli, S. P., Dobbs, T. D., ... \& Whitaker, I. S. (2020). Could Vitamins Help in the Fight Against COVID19?. Nutrients, 12(9), 2550. 
49) Chen, D., Oezguen, N., Urvil, P., Ferguson, C., Dann, S. M., \& Savidge, T. C. (2016). Regulation of protein-ligand binding affinity by hydrogen bond pairing. Science advances, 2(3), e1501240.

50) Bolton, S., \& Null, G. (1982). Vitamin B15: a review and update. Orthomol. Psych, 11(4), 260-266.

51) Barchetta, I., Carotti, S., Labbadia, G., Gentilucci, U. V., Muda, A. O., Angelico, F., ... \& Morini, S. (2012). Liver vitamin D receptor, CYP2R1, and CYP27A1 expression: relationship with liver histology and vitamin D3 levels in patients with nonalcoholic steatohepatitis or hepatitis C virus. Hepatology, 56(6), 2180-2187.

52) Beard, J. A., Bearden, A., \& Striker, R. (2011). Vitamin D and the anti-viral state. Journal of Clinical Virology, 50(3), 194-200.

53) Gal- Tanamy, M., Bachmetov, L., Ravid, A., Koren, R., Erman, A., Tur- Kaspa, R., \& Zemel, R. (2011). Vitamin D: an innate antiviral agent suppressing hepatitis C virus in human hepatocytes. Hepatology, 54(5), 1570-1579.

54) Hemilä, H. (2003). Vitamin C, respiratory infections and the immune system. Trends in Immunology, 24(11), 579-580.

55) Peng, Z. (2020). Vitamin C infusion for the treatment of severe 2019-nCoV infected pneumonia.

56) Dofferhoff, A. S., Piscaer, I., Schurgers, L. J., Visser, M. P., van den Ouweland, J. M., de Jong, P. A., ... \& Maassen, C. (2020). Reduced vitamin K status as a potentially modifiable risk factor of severe COVID-19. Clinical Infectious Diseases: An Official Publication of the Infectious Diseases Society of America.

57) Beck, M. A., Kolbeck, P. C., Rohr, L. H., Shi, Q., Morris, V. C., \& Levander, O. A. (1994). Vitamin E deficiency intensifies the myocardial injury of coxsackievirus B3 infection of mice. The Journal of nutrition, 124(3), 345-358.

58) Ross, A. C. (1996). Vitamin A deficiency and retinoid repletion regulate the antibody response to bacterial antigens and the maintenance of natural killer cells. Clinical immunology and immunopathology, 80(3), S63-S72.

59) Seeliger, D., \& de Groot, B. L. (2010). Conformational transitions upon ligand binding: Holo-structure prediction from apo conformations. PLoS Computational Biology. 6(1).

60) Marsh, Joseph A., and Sarah A. Teichmann. "Relative solvent accessible surface area predicts protein conformational changes upon binding." Structure 19.6 (2011): 859867. 
61) Pandya, M. D., Dabhi, S. D., Jha, P. K., \& Rawal, R. (2016). Targeting MLL-CXXC Domain with Synthetic $\mathrm{CpG}$ Dinucleotides: Docking and Molecular Dynamics Simulation Based Approach. In Advanced Materials Research, 1141, 115-120. Trans Tech Publications Ltd.

62) Dave, M. E. D. H. A., Daga, A. D. I. T. I., \& Rawal, R. A. K. E. S. H. (2015). Structural and functional analysis of AF9-MLL oncogenic fusion protein using homology modeling and simulation based approach. Int. J. pharm. Pharm. sci, 7(12), 155-161.

63) Pandya, M., Jani, S., Dave, V., \& Rawal, R. (2020). Nanoinformatics: An Emerging Trend in Cancer Therapeutics. Nanobiotechnology: Concepts and Applications in Health, Agriculture, and Environment, 135. 


\section{Figures}

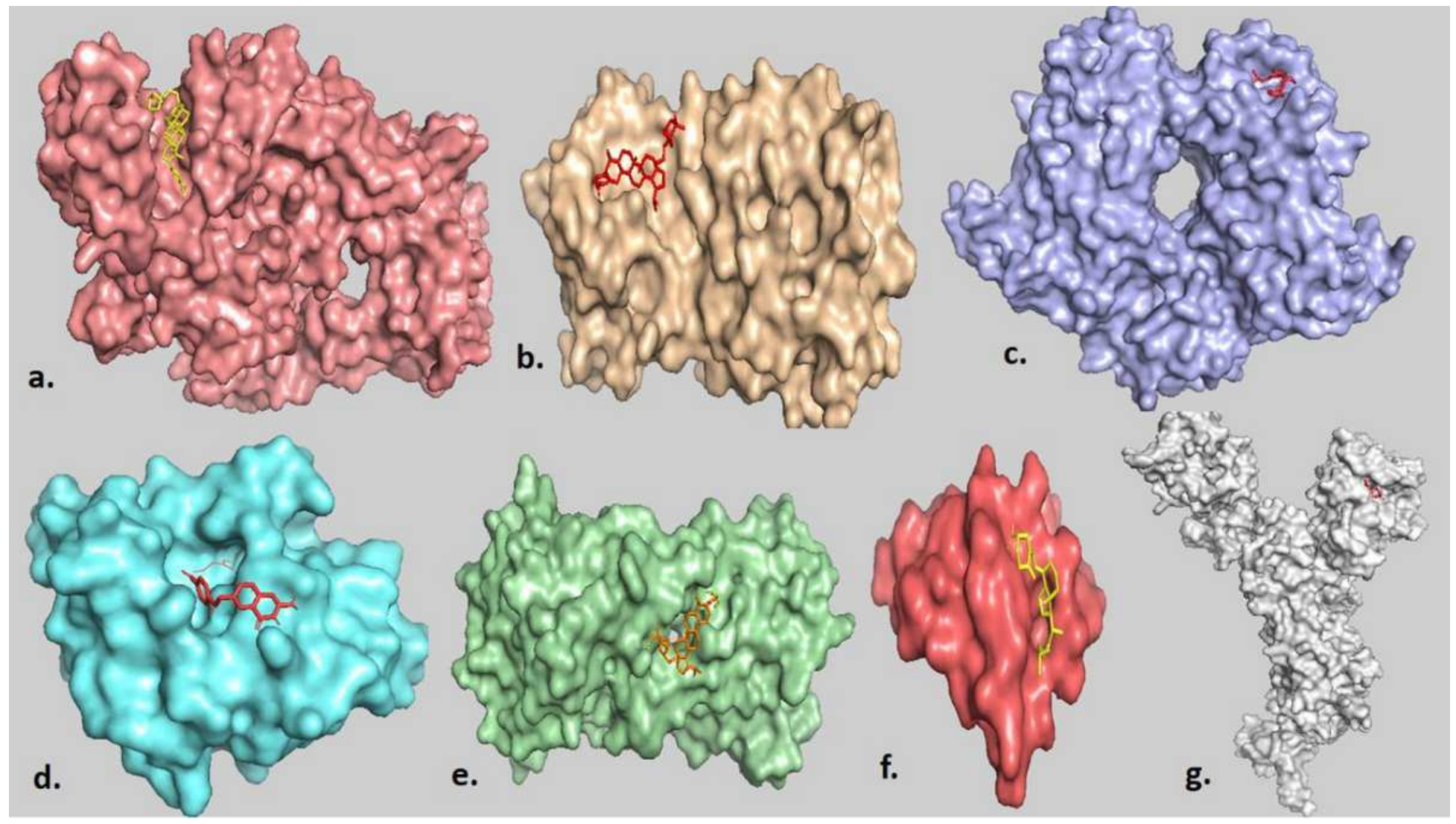

\section{Figure 1}

Top molecular interaction of SARS-CoV-2 Drug targets and vitamin: (a) RdRP-Vita.B12. (b) MPro-Vita.b12. (c) HE-Vita.D3. (d) NSP3-Vita.B9 (e) ORF3a-Vita.B12 (f) ORF7a-Vita.B12. (g) Spike-Vita.D3. 


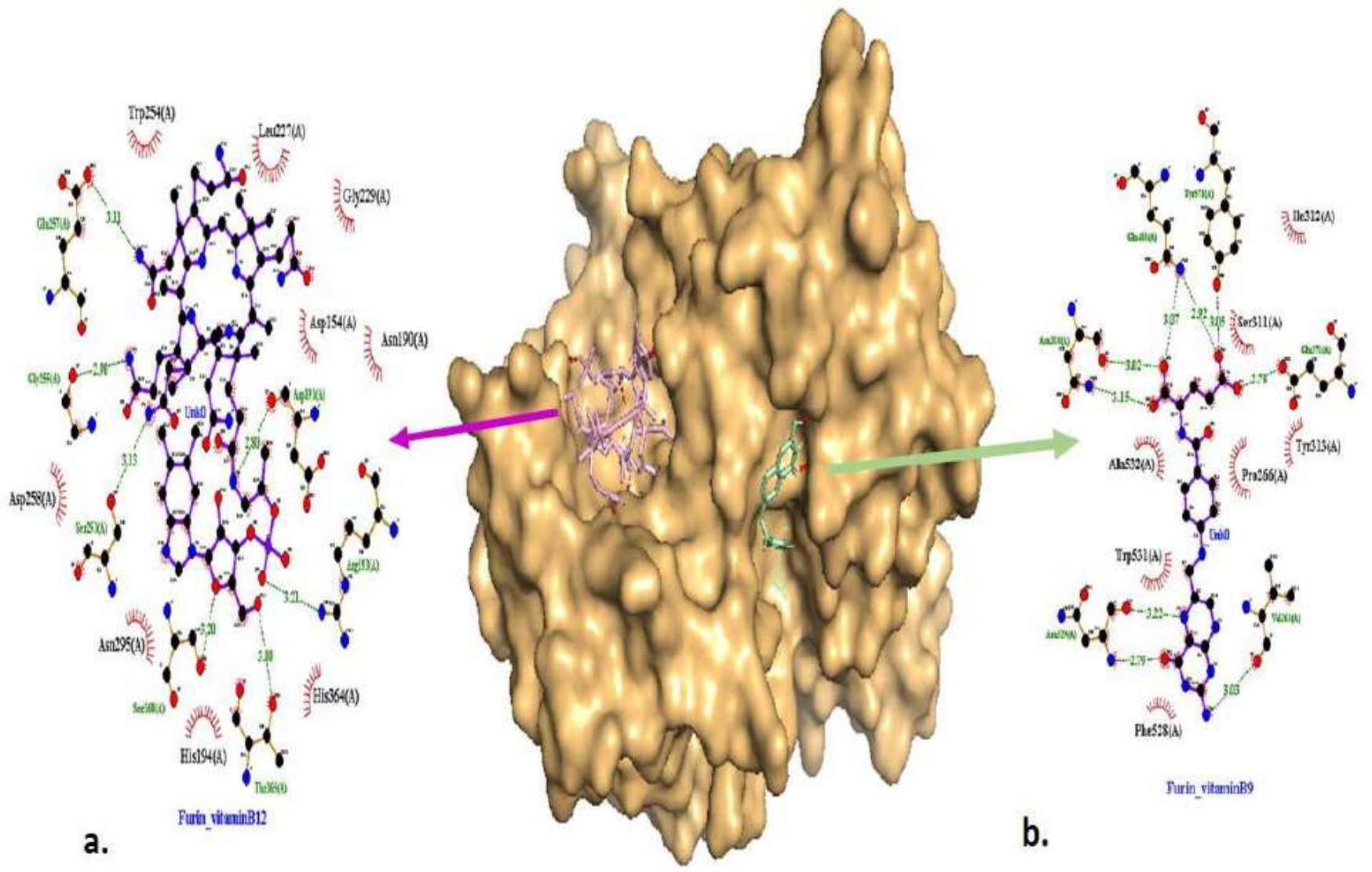

Figure 2

Interaction of furin residues with (a) vitamin B12 and (b) vitamin B9. 


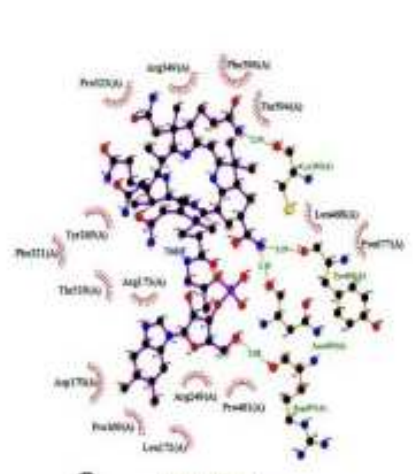

a.

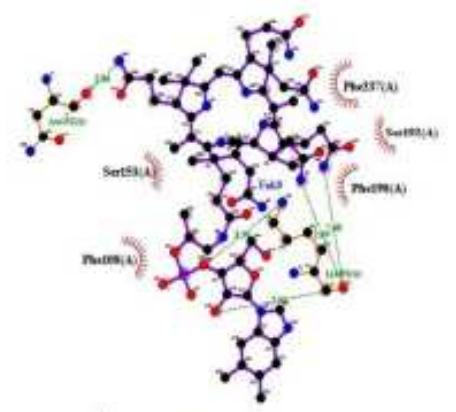

d. ma vumant

\section{VITAMIN B12}

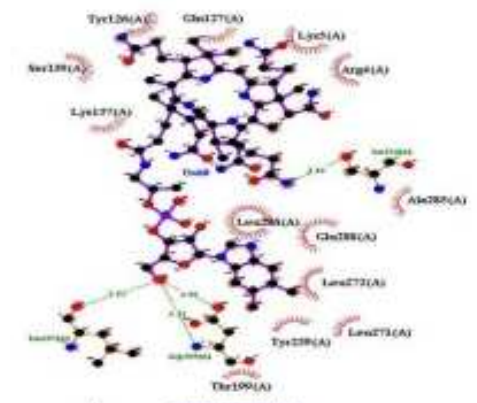

b.

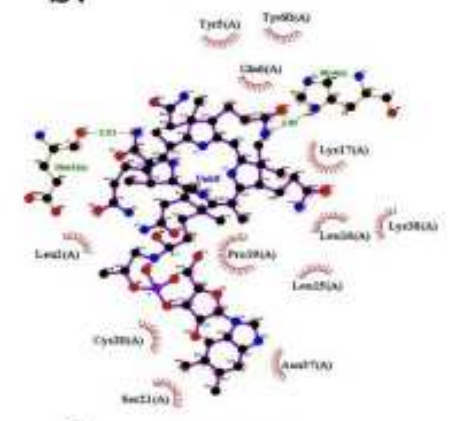

e.
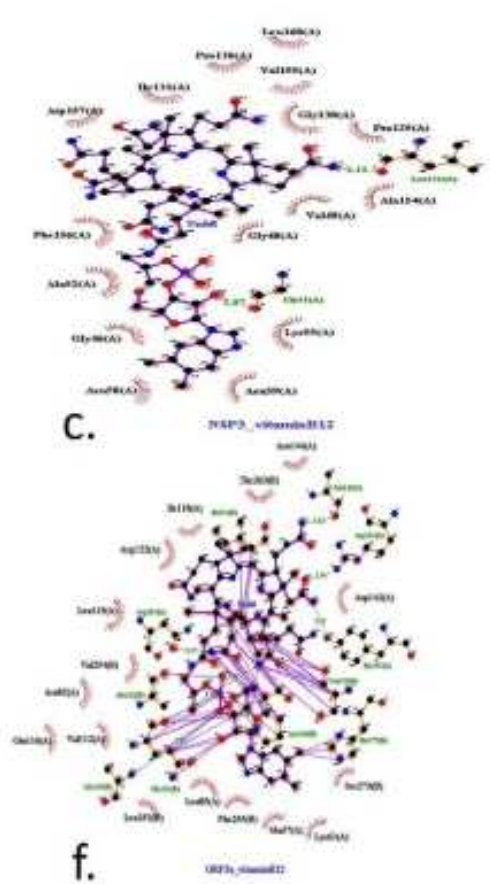

VITAMIN B9

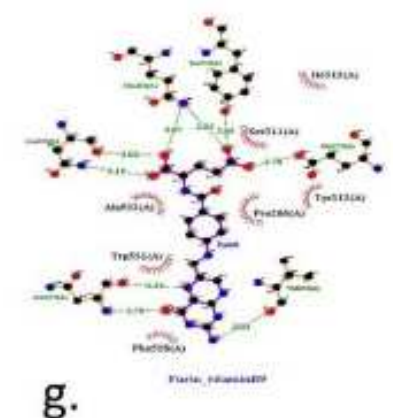

g.

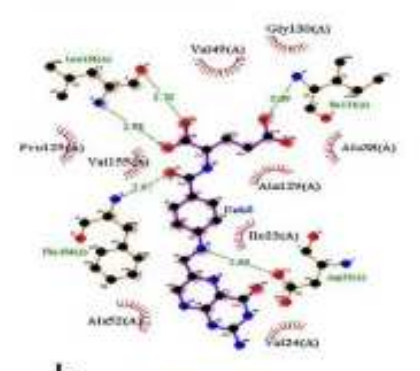

h. nspr.m.n.s.

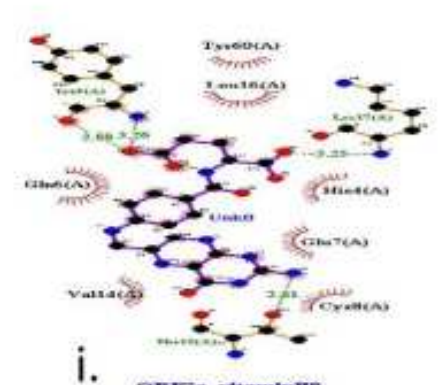

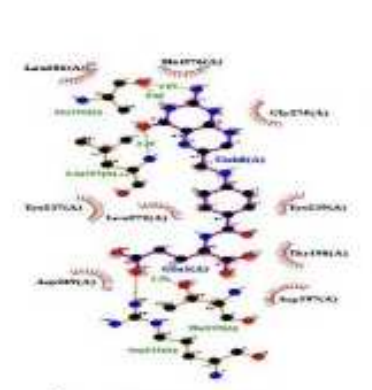

j.

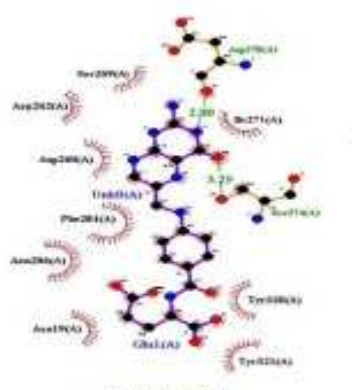

$k^{n}$.

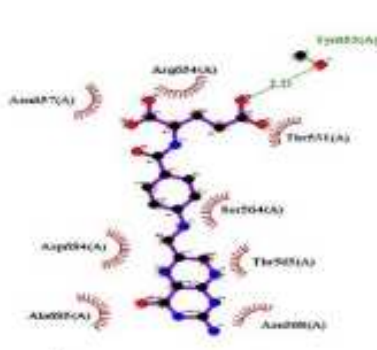

I. noux …는

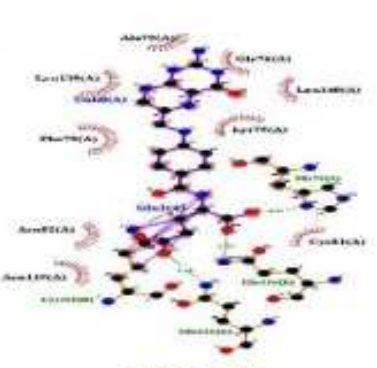

m.

\section{Figure 3}

Interaction plot of vitaminB12 and vitamin B9 with all viral targets. (a) RDRP-Vita.B12. (b) MPROVita.B12. (c) NSP3-Vita.B12. (d) HA-Vita.B12. (e) Orf7a-Vita.B12. (f) Orf3a-Vita.B12. (g) Furin-Vita.B9. (h) NSP3-Vita.B9. (i) Orf7a-Vita.B9. (j) MPRO-Vita.B9. (k) HA-Vita.B9. (I) RDRP-Vita.B9. (m) Orf3a-Vita.B9. 


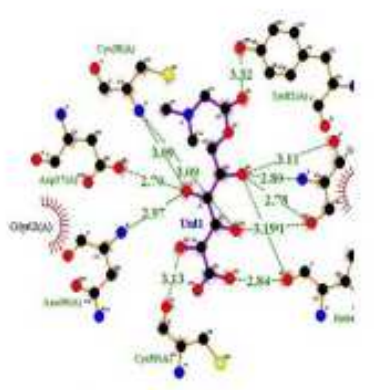

a. Ha_variatis

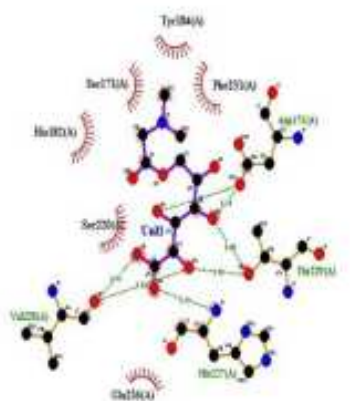

e. arby-thminats

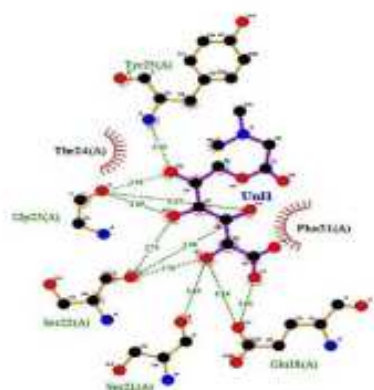

b.

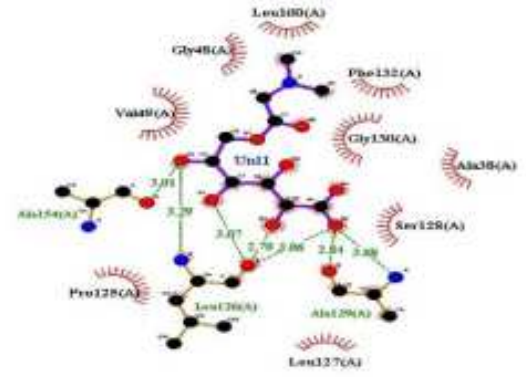

f. NSP3_vatamanBs

VITAMIN D3

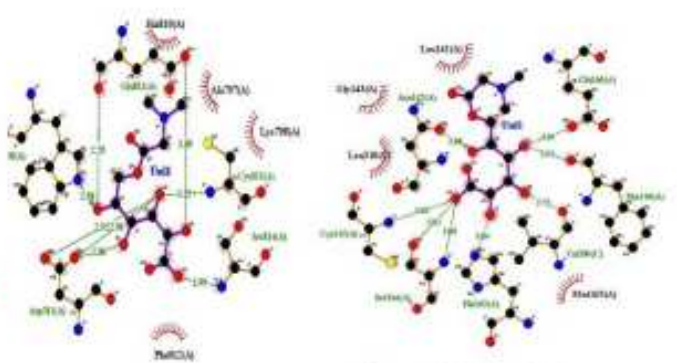

d. Meroo numatens

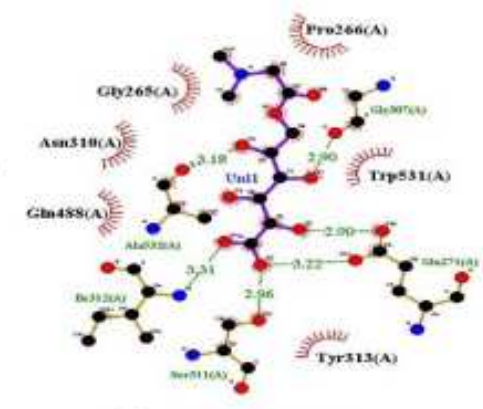

g. Furin_vituminBis

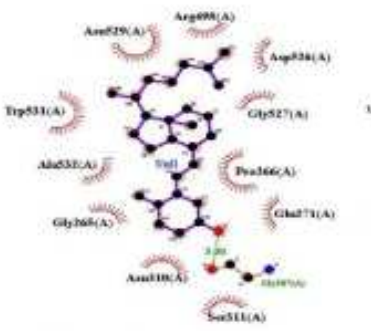

h. nutn numbers
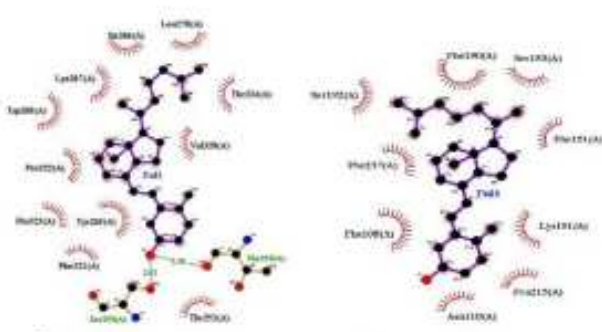

i. nas nomess

j.

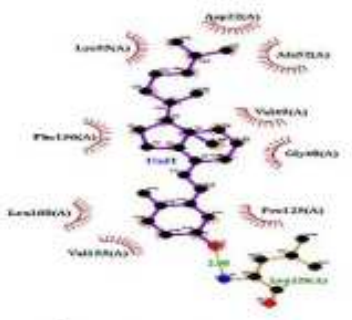

k. Nors …untams
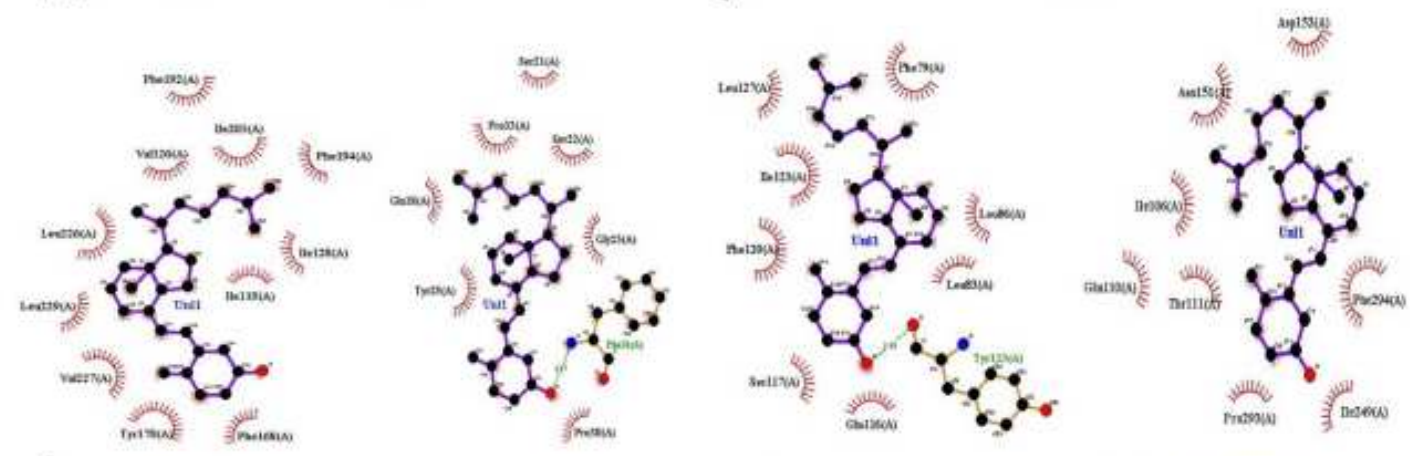

I. SPRE, viluminD

m. «rs zaminas

n. orpan_útamiinD3

O. MPRo Vituminds

\section{Figure 4}

Interaction plot of vitaminB15 and vitamin D3 with COVID-19 targets. (a) HA-Vita.B15. (b) Orf7a- Vita.B15. (c) RDRP-Vita.B15. (d) MPRO-Vita.B15. (e) Orf3a-Vita.B15. (f) NSP3-Vita.B15. (g) Furin- Vita.B15. (h) Furin-Vita.D3. (i) RDRP-Vita.D3. (j) HA-Vita.D3. (k) NSP3- Vita.D3. (I) SPIKE-Vita.D3. (m) Or7a-Vita.D3. (n) Orf3a-Vita.D3. (o) MPRO-Vita.D3. 
RMSD

a.

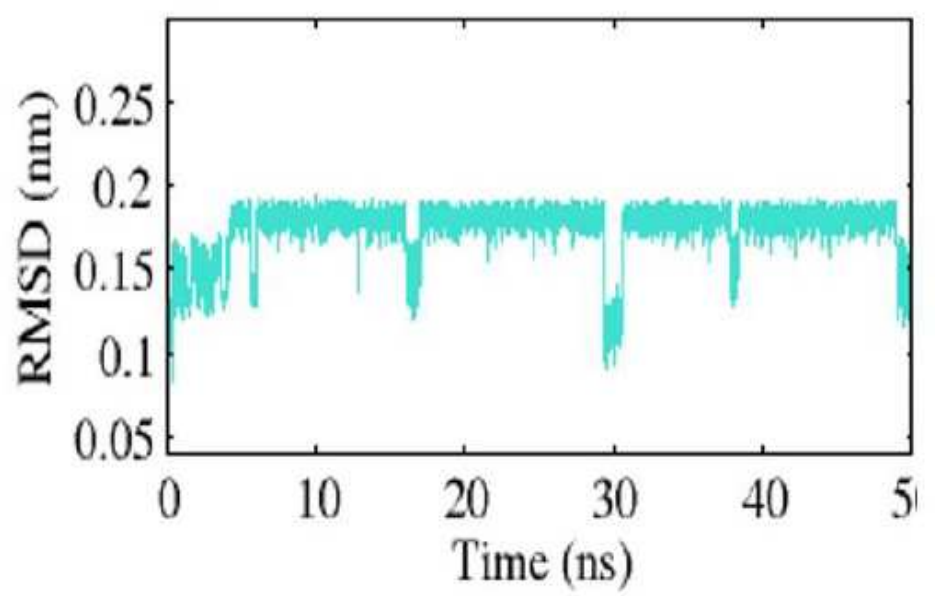

RMS fluctuation

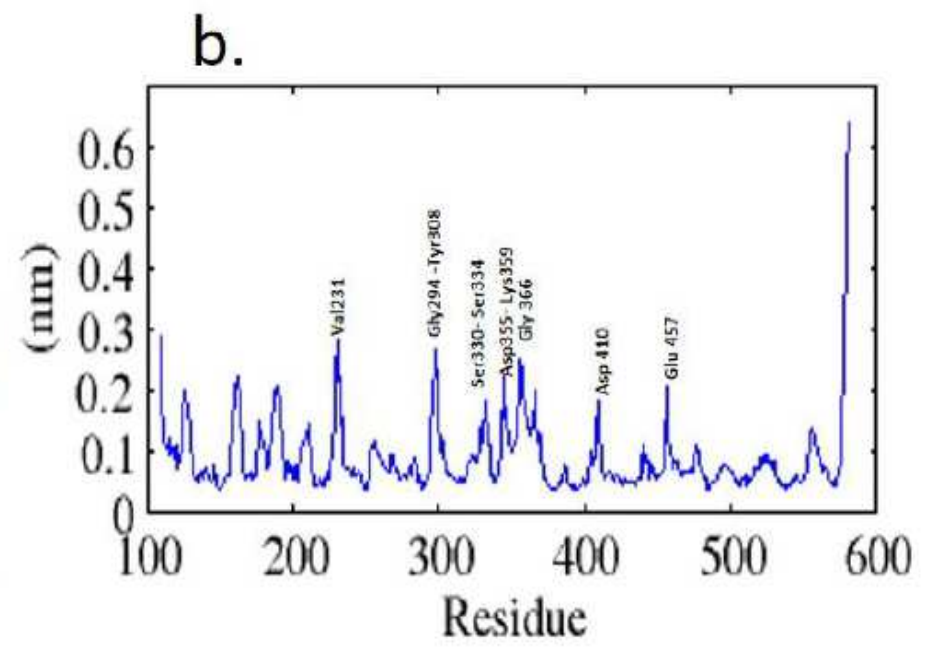

Figure 5

(a.) RMSD and (b.) RMSF trajectory of Furin-Vitamin B12 complexes obtained from 50 ns MD simulation.

Radius of gyration (total and around axes)

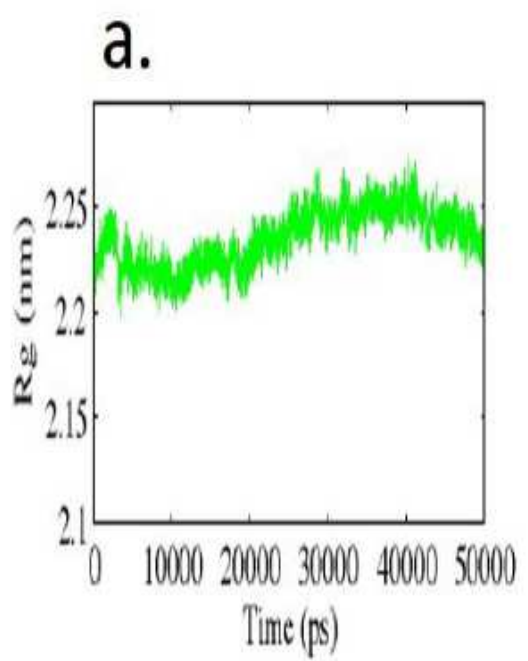

GROMACS Energies

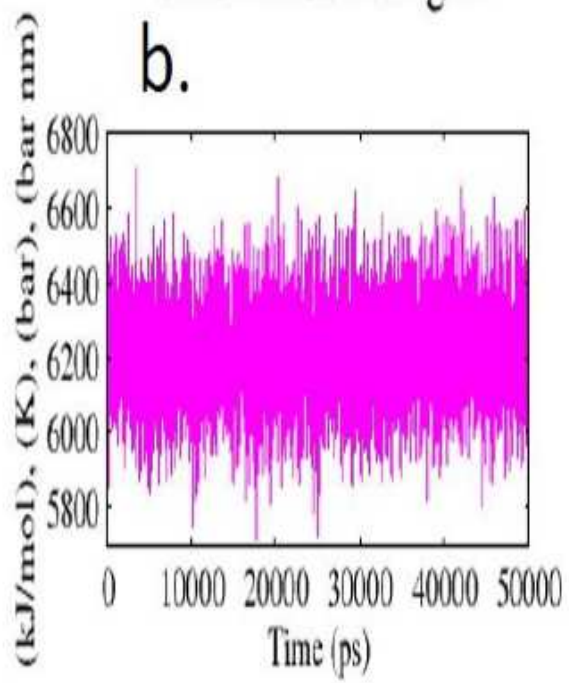

Solvent Accessible Sufface

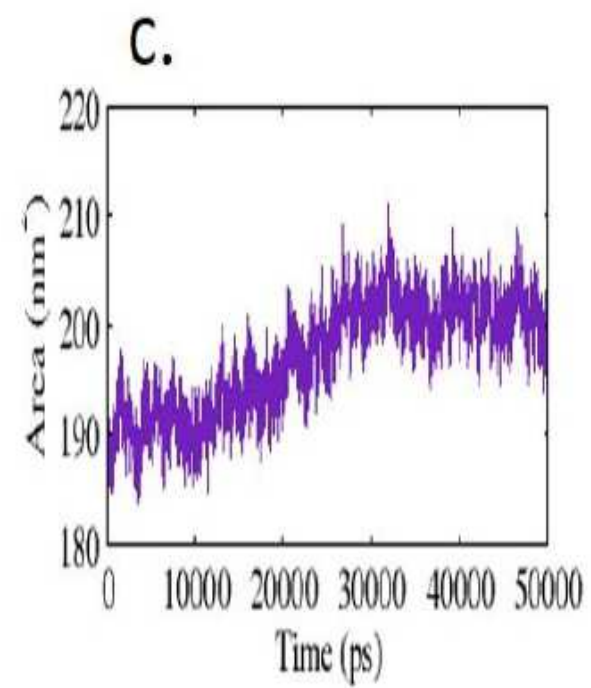

Figure 6

MD trajectories for (a) Radius of gyration (b) potential energy (C) Solvent accessible surface area.

\section{Supplementary Files}

This is a list of supplementary files associated with this preprint. Click to download. 
- supplimentaryfigures.pdf

- Supplimentarytable.pdf 